\title{
Santiago de las Atalayas: una ciudad de la frontera en el Nuevo Reino de Granada (XVI-XVIII)
}

\author{
Andrés Castro Roldán \\ Universidad de París III, Francia \\ marianne.barreau@neuf.fr
}

\section{Resumen}

Este trabajo es el fruto de una investigación doctoral sobre las misiones jesuitas en la frontera oriental del Nuevo Reino de Granada durante los siglos XVII y XVIII, realizada en varios archivos coloniales. Su objeto es la comprensión de la colonización laica y su interacción con la misión a través del estudio del caso de Santiago de las Atalayas, ciudad fronteriza erigida por los vecinos de Tunja en 1588 en las inmediaciones del territorio de Casanare, donde se desarrolló la evangelización jesuita.

Palabras clave: misiones jesuitas, Nuevo Reino de Granada, frontera, llanos orientales, siglos XVII y XVIII.

\begin{abstract}
This article is the result of a doctoral thesis research conducted in several colonial archives about Jesuit Missions on the eastern frontier of the New Kingdom of Granada during the 17th and 18th centuries. The objective is to understand how the lay colonists interacted with the Missions, through the case study of Santiago de las Atalayas, a frontier city founded by the inhabitants of Tunja in 1588 on the foothills of the territory of Casanare where Jesuits were actively working at the same time.
\end{abstract}

Key words: Jesuit missions, Nuevo Reino de Granada, frontiers, llanos orientales, $17^{\text {th }}$ and $18^{\text {th }}$ centuries.

\section{Introducción}

En el territorio fronterizo situado al oriente del Nuevo Reino de Granada, la fundación de ciudades correspondió con las empresas llamadas de pacificación organizadas desde finales del siglo XVI para extender el dominio español hacia la Orinoquía. Sin embargo, la vastedad de los territorios y el nomadismo de los 


\section{FRONTERAS}

de la fistoria

indios del piedemonte y el llano hicieron difícil y caótico este proceso. Aunque las tribus "amigas" aceptaban en un principio la convivencia, abandonaban fácilmente sus pueblos y cambiaban de asiento con el invierno y el verano, las crecientes de los ríos, o las migraciones rituales. De ahí la dificultad que tuvieron los colonos para reducir tribus como los tunebos, guayupes, jirajaras, guahibos y chiricoas.

Durante la primera mitad del siglo XVII, estas dichas "ciudades" vivieron en la anarquía de un sistema esclavista, supeditadas al el proceso de conquista de indios. Sus vecinos pasaban de unas ciudades a otras en función de las noticias de nuevas entradas, o hacían fundaciones cuando lo requerían las circunstancias. Además la contribución a la vida de la estancia fue para estos españoles más importante que la efectuada en su calidad de vecino o ciudadano, pues la jurisdicción municipal se extendía en muchos casos por cientos de millas, haciendo de ellos, ante todo, soldados y terratenientes. Medina de las Torres, San Agustín de Cáceres, Espinosa de las Palmas, Nuestra señora del Caguán, San Martín del Puerto, Santa María de la Rosa, San Joseph de Crabo y Gran Ciudad de Sófraga fueron algunas de estas ciudades efímeras que aparecieron y desaparecieron a lo largo del siglo XVII en función de las necesidades de conquista y las estrategias geográficas de defensa y pacificación. Muchas fueron solamente puestos de avanzada, bastiones o cuarteles pomposamente bautizados como ciudades.

La llegada de los primeros jesuitas al Casanare hacia 1655 presenta una primera ruptura en la historia de estas conquistas de indios. La impugnación de lo que hasta los años 1640 fue costumbre aceptada por los colonos, convirtió poco a poco a la institución misional en la piedra de toque del proceso de colonización llanera. Hasta finales del siglo XVII la coexistencia del espacio de coloniaje y el misional implicó luchas de poder y problemas de cohabitación. Sin embargo, el espacio misionan fue integrando progresivamente a los colonos y mestizos dentro de las redes de haciendas y pueblos de indios establecidas por los jesuitas. Ya desde 1650 el proceso económico-espiritual de la misión implicó una mayor estabilidad en los asentamientos y ciudades.

Es este el caso de Santiago de las Atalayas, ciudad que logró consolidarse en la segunda mitad del siglo XVII como la más importante ciudad de españoles, centro económico importante y motor de la colonización laica del llano. De Santiago podemos seguir la huella desde su fundación en 1588, hasta su decadencia en el siglo XVIII, a través de los documentos de visitas, peticiones, informes, mercedes, capitulaciones, cartas y crónicas antiguas, documentos por 
los cuales sabemos que en su vida de más de 330 años mudó por lo menos cinco veces de lugar. Del trazo físico de uno de estos asientos, no queda hoy más rastro que unas ruinas en el municipio de Agua Azul y los nombres de Pueblo Viejo de Cusiana y Santiago de las Atalayas con que se bautizaron allí mismo dos de los más grandes pozos petroleros de Colombia.

\section{Linaje, encomiendas y continuidad de poder de los primeros colonos}

La historia de Santiago de las Atalayas está íntimamente ligada con la de sus encomenderos y tratantes de indios, organizados en clanes ${ }^{1}$ de familia a través del poder heredado que ejercieron como poseedores de indios, terratenientes, cabildantes y tenedores de oficios de gobierno. Sus vecinos más sobresalientes aparecen en los documentos oficiales con los cargos de gobernadores, corregidores, tenientes de gobierno, maestres de campo, capitanes, cabos, alférez, alguaciles, alcaldes, justicias mayores, clérigos, cofrades o frailes, todos dedicados a las conquistas de indios, los obrajes del algodón y las estancias de ganado mayor. Tres clanes familiares de la ciudad de Tunja parecen haber sido la matriz de la fundación de esta ciudad y de su consiguiente continuidad histórica: los Daza, los Alarcón y los Suárez de Vargas. Todos, con su raíz en las encomiendas del corregimiento de Sogamoso.

El fundador de Santiago, Pedro Daza Segundo, era hijo del capitán Pedro Daza de Madrid Erazo y nieto del capitán Juan de Madrid que había venido de España entre los 200 soldados que acompañaron a Gonzalo Jiménez de Quesada. Pedro Daza de Madrid era vecino de la ciudad de Tunja donde había obtenido la encomienda de los indios de Pesca y Bombaza en 1539 (Colmenares 174). A su muerte en 1550 le sucedió en ella su hijo Pedro Daza Segundo haciéndose adjudicar además las de Tobasia, Nomegira, Toquechá y Moquetá. Desde estas tierras, próximas al camino indígena del llano, Pedro Daza Segundo, emprendió la expedición de pacificación de los cusianas y la fundación de la ciudad de Santiago de las Atalayas. Su hijo, Pedro Daza Mejía, heredaba en tercera vida por composición dichas encomiendas a las que se agregaban en 1601 las de Chámeza y Cusiana de indios achaguas (llaneros) y que más tarde pasarían a sus

\footnotetext{
${ }^{1}$ Uso aquí la palabra clan en su acepción común de grupo predominantemente familiar unido por fuertes vínculos y tendencias exclusivistas. Sin entrar en matices etnológicos, lo que se quiere resaltar aquí es el nexo entre la consanguinidad, la territorialidad y el poder que la palabra clan implica, tal y como es utilizada en Europa por la historiografía medievalista. Germán Colmenares subraya la importancia de los linajes de las familias de conquistadores y su relación a la territorialidad a través de la institución de la encomienda.
} 


\section{FRONTERAS}

de la historia

hijos Juan Daza Pérez Godoy en 1635 (Chámeza y Cusiana) y Pedro Daza y Olarte en 1642 (Pesca y Bombaza). El hijo de este último, Pedro Daza y Espeleta, lograba todavía en 1680 hacerse adjudicar la encomienda de Chámeza y Cusiana, que iba por su tercera vida. Este Daza gobernó en nombre de su clan la ciudad de Santiago en 1684, casi 100 años después del gobierno de su bisabuelo y fundador.

El linaje de los López de Alarcón se inaugura con el matrimonio de María Daza de Erazo, hermana del fundador de Santiago Pedro Daza Segundo, con el capitán Bartolomé Alarcón de Ocón, conquistador de la provincia de la Grita y teniente de gobierno de la ciudad de Altamira de Cáceres (Vilar y Pascual 64). Bartolomé había obtenido por 1591 las encomiendas de Toquechá y Moquechá también en el corregimiento de Sogamoso por muerte del fundador de Santiago de las Atalayas (Colmenares 27). Su hijo Pedro de Alarcón fue poblador y cofundador de la ciudad de Medina de las Torres, antecedente de la de Santiago de las Atalayas. Pedro de Alarcón heredaba la encomienda de su padre en 1635 (Ruiz 396). Su nieto Cristóbal López Navarro fue, al igual que su abuelo, teniente de gobernador y fundó junto con Adrián Suárez de Vargas la ciudad de San Martín del Puerto. Su bisnieto Pedro López de Alarcón fue padre de Bartolomé de Alarcón, gobernador de Santiago hacia 1684.

El abolengo de los Suárez de Vargas se origina en Diego Suárez Montañés, regidor perpetuo de Tunja quien contribuyó en la fundación de Santiago con sus indios de Tota encomendados por 1562 abriendo como veremos el camino entre Sogamoso y Santiago (Colmenares 172). Su hijo Diego Suárez Bustamante heredó en segunda vida esta encomienda y a su muerte lo sucedió su nieto Diego Suárez de Vargas en 1601. La encomienda de Tota siguió en la misma familia pues en 1625 era adjudicada a Francisco Suárez de Vargas hijo en segundo matrimonio de Diego Suárez Montañés (Ruiz 396). En 1635 el Marqués de Sófraga otorgaba por composición esta encomienda a su nieto Pedro Ordóñez y Vargas, gobernador de Santiago. A finales del siglo XVII y más de 100 años después de su fundación el maestre de campo Pedro Suárez de Vargas, nieto del anterior, era uno de los hombres más poderosos de Santiago. 


\section{Gráfica 1. Linaje de los Daza-Alarcón}

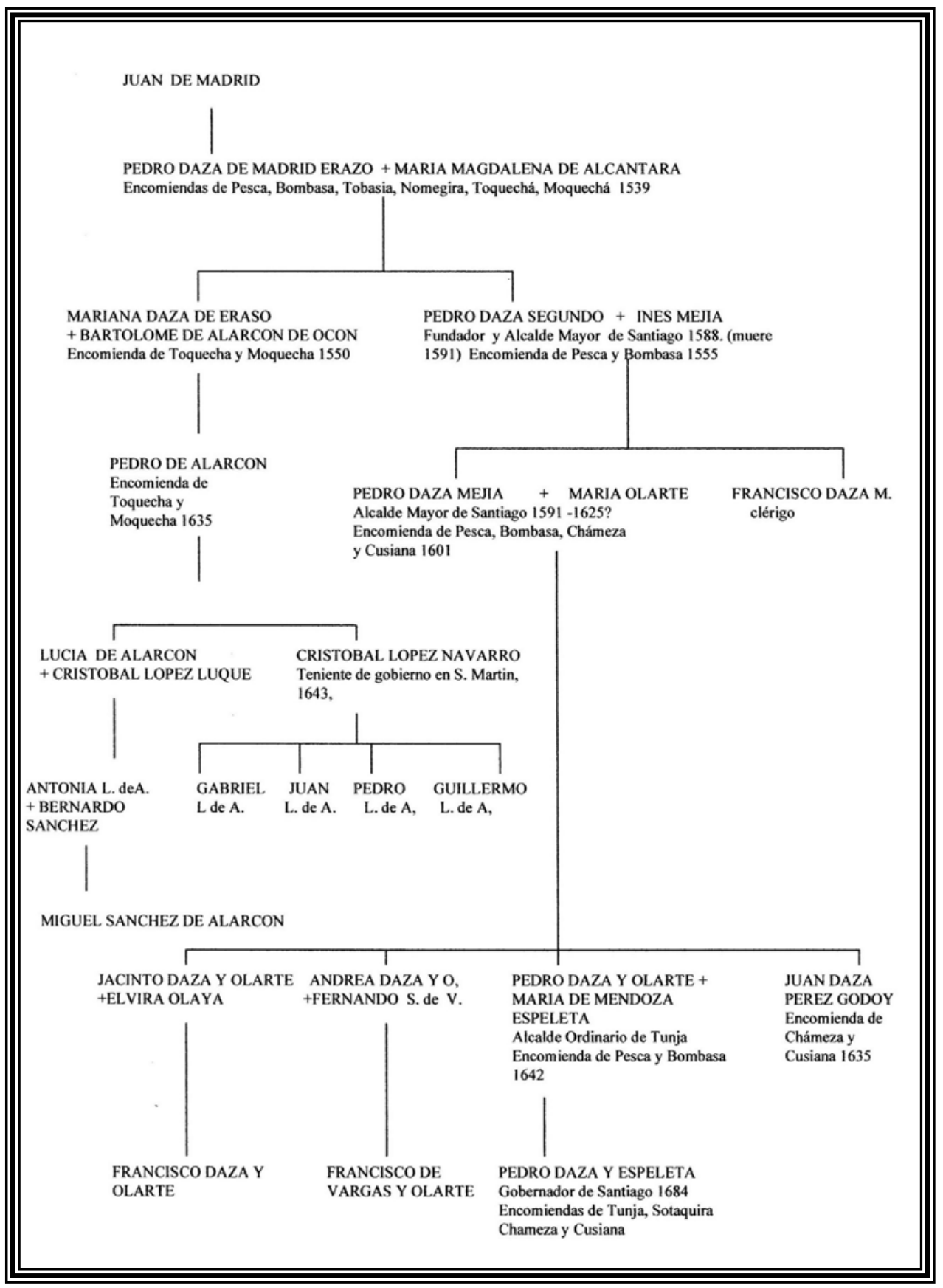


FRONTERAS

de la fistoria

\section{Gráfica 2. Linaje de los Suárez de Vargas}

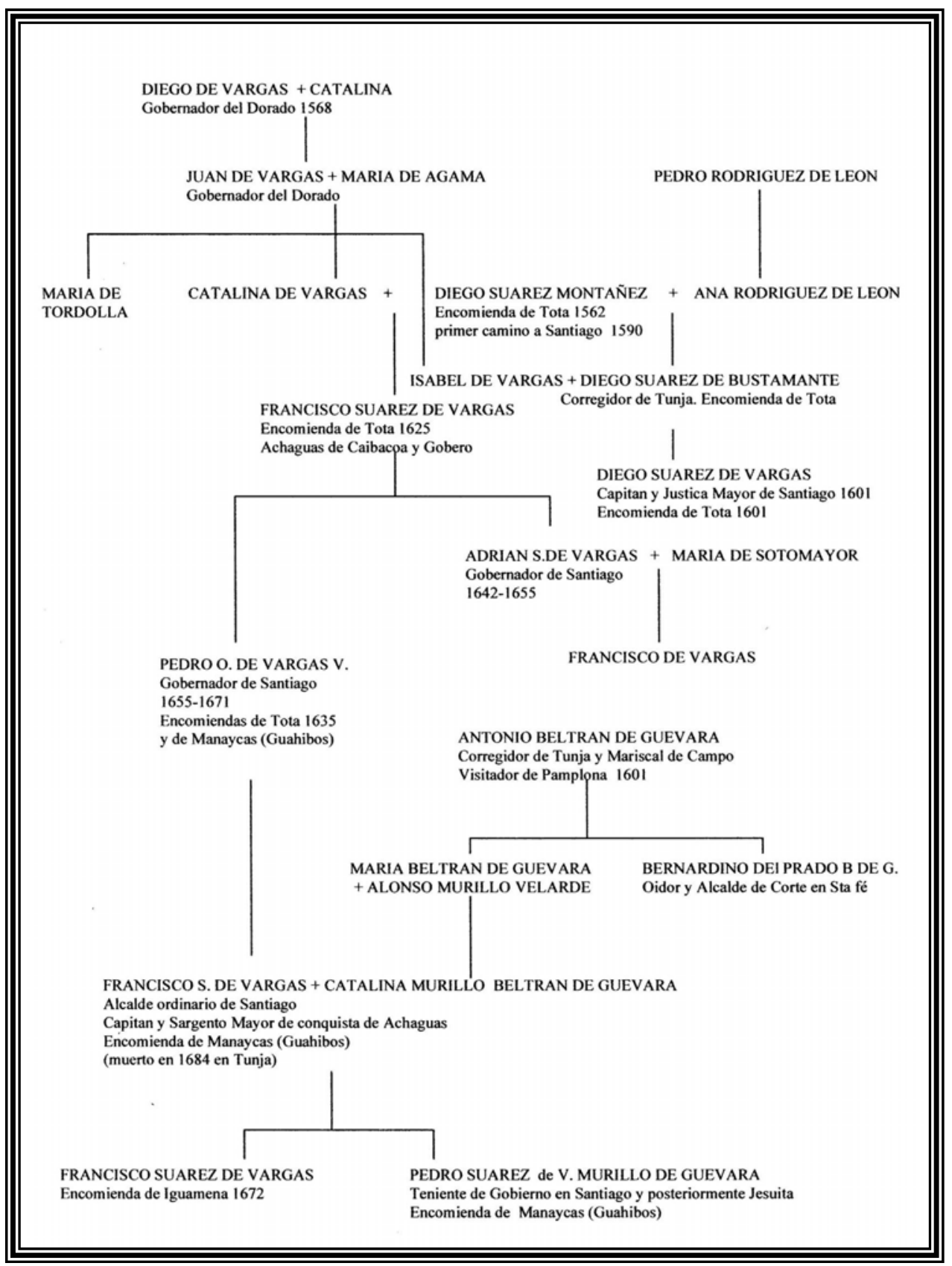


Como vemos, la pequeña élite de Santiago, mantuvo su hegemonía gracias a su pertenencia al linaje de los conquistadores. El prestigio social de su calidad de beneméritos, junto con la riqueza de sus haciendas y el poder de sus alianzas les permitieron en muchos casos conservar las encomiendas de sus antepasados hasta el siglo XVIII. Aunque por regla general las mejores encomiendas se reservaron al hijo mayor, también podían pasar a otros en virtud de las particiones de pueblos o de nuevas conquistas, o incluso pasar a manos de otra familia por matrimonio, como fue el caso de la familia Alarcón. En esto, como lo señala Germán Colmenares, la sociología de la sucesión de la encomienda es bastante diferente de la del mayorazgo español (24).

Estas familias, de las que no hemos citado arriba más que su rama principal, eran, no obstante, muy numerosas si tomamos en cuenta la multitud de vástagos de las familias nobles. Los que no heredaban, constituyeron una aristocracia rural pobre que conformó el grueso de los vecinos de estas ciudades, de por sí poco numerosas. Algunos pasaron a poblarse con sus esposas legítimas, aunque es probable que por las incomodidades de los caminos y de la vida en estas regiones aisladas la mayoría vivieran amancebados con mujeres mestizas o indias.

Los principales vivían, de hecho, en la ciudad de Tunja, aunque legalmente fueran también vecinos de los llanos. Pedro Ordóñez y Vargas, por ejemplo, a pesar de gobernar la ciudad de Santiago entre 1656 y 1671, vivía parte del año entre la ciudad de Tunja y su encomienda de Tota. También fue el caso de Pedro Daza Mejía, tercero de su nombre, quien aunque era alcalde mayor de Santiago continuó avecindado en la ciudad de Tunja, donde poseía su encomienda de Pesca y Bombasa. De su matrimonio legítimo con María de Olarte tuvo a Marina, Petronila, Helena, Jacinto, Francisco, Agustín, Pedro y Juan, todos avecindados en Tunja y Santafé, salvo Juan Daza Pérez Godoy quien fue encomendero de Chámeza y Cusiana y al parecer vivió entre Santiago y Tunja (Vilar y Pascual 64). Estos hijos segundones poseyeron en el mejor de los casos pequeñas encomiendas, pero sobre todo se convirtieron en propietarios de haciendas de pan coger, de caña de azúcar, algodón y de estancias de ganado mayor y menor. Algunas de las hijas principales fueron monjas en Tunja o tuvieron mejor suerte al casarse con ricos comerciantes, encomenderos ya establecidos o funcionarios del gobierno de Santafé, perpetuando así el linaje y el poder local que detentaban, pues de una $u$ otra forma, y pese a las prohibiciones y restricciones del sistema de encomiendas, estos clanes de familia consiguieron mantener su dominio sobre el llano por más de seis generaciones. 


\section{Las encomiendas de Tunja: base de las primeras edificaciones (1585- 1625)}

Estas tres familias pudieron mantener el control de la región de Santiago mediante sus encomiendas de Sogamoso, cuyas parcialidades indígenas habían garantizado tradicionalmente durante la época prehispánica el intercambio económico entre las tierras altas y la región del piedemonte y el llano. En este sentido la institución de la encomienda garantizó la continuidad de la tradición prehispánica del comercio del algodón, que pasó de las manos del cacique Tundama y sus súbditos a las de las familias de encomenderos de la ciudad de Tunja. Estos indios fueron los verdaderos fundadores y colonizadores del llano, pues se encargaron de garantizar y mantener los nexos económicos, de construir y mantener ciudades y caminos, recoger, condicionar, hilar y transportar el algodón hasta las tierras altas. Esto explicaría que hasta mediados del siglo XVII, la población indígena, se haya limitada al piedemonte, esencialmente en los pueblos de Chámeza, Cusiana y Labranzagrande, donde se concentraban las labranzas de algodón. Esta primera fase de colonización se habría efectuado mediante la migración de los indios de las tierras altas al piedemonte llanero. Los traslados de indios de las encomiendas de Pesca, Bombasa, Toquechá, Moquechá, Tota y Chámeza debieron haber constituido la primera base poblacional del núcleo santiagueño y explicarían la vocación algodonera de la región hasta el siglo XVIII.

Por el contrario fueron pocas las encomiendas que se fundaron en pueblos con los indios llaneros (achaguas, guahibos, chiricoas, sálivas) durante los 100 años de dominación de estas familias de encomenderos. Las encomiendas del altiplano cundiboyacence fueron pues el punto de partida de la colonización. Así, los corregimientos de Sogamoso y Chita dieron nacimiento más adelante a las gobernaciones de Santiago dominada por los Daza, los Suárez de Vargas y los Alarcón, y a la de Casanare controlada en un principio por los Berrío/Mendoza y cedida más adelante a la Compañía de Jesús en la segunda mitad del siglo XVII.

El primer antecedente de Santiago de las Atalayas fue la ciudad de Medina de las Torre, fundada hacia 1585 con la intención de explotar las posibles minas de aluvión que se descubrieran. Pedro Daza había emprendido su asentamiento, a instancias de su cuñado, Bartolomé Alarcón de Ocón, conquistador de la provincia de Barinas, quien era entonces teniente de Francisco de Cáceres, gobernador de la Grita (Simón 4: 49; Vilar y Pascual 64) La ciudad fue 
instalada en el piedemonte andino a inmediaciones de los llanos de San Juan ${ }^{2}$. Daza había encontrado allí los valles de Camami y Yemamo poblados de indios guayupes que habían venido aparentemente de paz y que vivían "en el río llamado Guacubia que viene por las espaldas de guayabita" (AGI, $S 51$, r. 2 , núm. 26, f. 2). Estos guayupes eran sobrevivientes de las múltiples expediciones que los usaron y abusaron para las conquistas del Dorado y eran por consiguiente hostiles a poblarse con los españoles. Esto explica la actitud del gobernador Cáceres quien dos meses más tarde, el 12 de mayo de 1585, escribía al rey pidiendo que se le diera merced de 1.000 indios de los de "Suma Paz de Bonbasas que comúnmente se llaman sutagaos" (AGI, $S$ 51, r. 2, núm. 26, f. 18). Estos indios, al igual que ciertas parcialidades de teguas, eran en efecto vecinos de los dichos guayupes (Mora 7) y como el presidente Venero de Leyva los había puesto por los años 1570 en la real corona, Cáceres pedía merced para que de nuevo se le encomendaran. Pedía igualmente facultad para "repartillos y premiar a los soldados conforme a sus trabajos y meritos" (AGI, $S$ 51, r. 2, núm. 26, f. 18). Pero estas tentativas parecen haber sido infructuosas, visto el clima de hostilidad que reinaba en la Audiencia contra Cáceres, enemigo de los Quesada. Medina de las Torres no prosperó lo que era lógico pues sin los indios de las tierras altas la conquista del llano era imposible ${ }^{3}$. Más lógico parecía emprender nueva fundación 35 leguas al norte, deshaciéndose de la jurisdicción del gobernador Cáceres y entrando en la de la ciudad de Tunja. En efecto, por capitulación de mayo de 1588 la audiencia encargaba a Pedro Daza poblar la

\footnotetext{
${ }^{2}$ En el acta de fundación, levantada el 23 de marzo de 1585 se describen así sus términos y límites: "desde el río grande de San Juan de los Llanos tomando la cordillera en la mano izquierda hasta dar en el río de Guatiguia dejando el pueblo de la sal e indios del en terminos del dicha ciudad de Medina de las Torres y viniendo por la cordillera y valle de Çaray [...] corriendo por la cordillera de Guatavita y Guabeta tomando las cordilleras de Garagoa y Somondoco hasta dar en la cordillera de Pongos y subiendo por la cordillera por las culatas de Josaca y culatas de Morcote hasta dar al río de Meta y cien leguas los llanos adentro hasta dar al Mar del Norte"(AGI, $S$ 51, r. 2 , núm. 26, f. 3).

${ }^{3}$ Medina de las Torres es mencionada por los cronistas Simón (4: 490) y Flores de Ocáriz en el siglo XVII, como cabeza de gobierno de capitulación, aunque es probable que se trate de la ciudad de San Martín del Puerto, que algunos autores reconocen ser la reedificación de la antigua Medina. "San Martín fue fundado en 1585, en sitio distinto con el nombre de Medina de las Torres, y posteriormente trasladado al lugar que hoy ocupa, a orillas del caño Camoas y en el borde de un ligero pliegue del terreno, que, con ser tan pequeño le da un magnífico golpe de vista, dominando la ilimitada llanura por el Oriente, por el Norte y por el Sur" (Restrepo 334). También con el nombre de Medina fundó por los años 1620 el dominico fray Alonso Ronquillo un pueblo de indios chios, mambitas y suraguos en los llanos de San Juan (Zamora 3: 169). El nombre de Medina aparecía aún en los mapas de caminos de la comisión corográfica de 1856 que situaba esta ciudad en las cabeceras del rió Umea, más o menos en la misma localización que aparece en la descripción de Daza (Gómez et al. 146).
} 


\section{FRONTERAS}

de la historia

tierra de la provincia de "Cusiana y Achaguas" y repartir sus indios entre los soldados. Se le concedía, además de las facultades de poblar, repartir la tierra y nombrar lugartenientes y alcaldes, el derecho de poseer la mejor encomienda de sus descubrimientos por dos vidas y de conservar la que ya poseía como vecino de Tunja por herencia de su padre. También se le concedía el título de alcalde mayor para él y su hijo (AGN, $V B$ 1, ff. 516-517).

En septiembre del mismo año, Pedro Daza fundó oficialmente la ciudad de Santiago de las Atalayas "para agora y siempre jamás" y "con aditamento que si se hallare un mejor sitio y lugar se mude"4. Esta segunda tentativa de Daza no duraría sino tres años, pues en 1591 los indios quemaron la población y mataron su fundador, dice la crónica, "por ocasión de un bofetón que dio a un indio principal porque defendía una muchachuela, hija suya, que el Daza le quería sacar de su casa y llevarla a su mujer" (Simón 4: 513). En la última década del silgo XVI, el cabildo de Tunja emprendió el segundo intento de fundación encargando el castigo de los indios y la reedificación de la ciudad al capitán Alonso Carrillo. Diego Suárez Montañés, regidor perpetuo de Tunja, abrió el primer camino al llano conectando el corregimiento de Sogamoso con la nueva población gracias a los indios de Tota que le habían sido encomendados desde

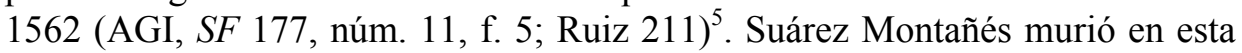
proeza, dicen los documentos, en un arcabuco de esta ruta.

A la muerte de Pedro Daza, Pedro Daza Mejía, tercero de su nombre, heredaba el título de alcalde mayor de la ciudad junto con las encomiendas de su padre (Ruiz 369). También heredaba de éste su propensión a abusar de los indios pues

\footnotetext{
${ }^{4}$ Los términos señalados fueron "desde el río grande de Megunpá, quedando todos los indios que hay de la otra banda del dicho río en términos de esta ciudad, corriendo la cordillera adelante a dar a las cordilleras altas de los Teguas y Chanza, Valle de la Sal, prosiguiendo por la misma cordillera hasta dar en la quebrada que dicen de Agavita donde se junta el rio Avita, prosiguiendo el río arriba hasta el dicho de Bujia, quedando los cerros de la sal en terminos y jursidiccion de esta ciudad y de alli siguiendo la misma cordillera de treinta leguas adelante hasta caer a los llanos e corriendo los llanos abajo en contorno e circuito de esta dicha ciudad. Señalo asimismo, treinta leguas hasta dar a la vuelta al río Piare donde se junta con el dicho río Mengupá". Véase "Acta".

${ }^{5}$ El camino bajaba de Sogamoso hasta Pueblo Viejo en la laguna de Tota y desde allí se descendía por el páramo de Toquilla hasta llegar al valle de Chámeza. De Chámeza a Santiago había más de 15 leguas de camino vadeando los ríos Suncé, Recetor y Bujia y descendiendo luego hasta el llano por las faldas de un macizo montañoso. Fue por estos cerros dice Codazzi en 1856 "que los conquistadores pudieron bajar al llano y fundar al pie de los cerros, la ciudad de Santiago de las Atalayas, cuyos escombros existen aun en una lomita cerca del río de este nombre" (Gómez et al. 99).
} 
el visitador Enríquez le acusaba en 1601, entre otras muchas, cosas de azotar y dar coces a uno de sus encomendados "que le pedía compensación por la muerte accidentada de un indio al volcar una canoa", de cometer excesos en los tributos y abuso por servicios personales pues a los indios de Pesca dice la visita "los llevaba dos y tres caminos de leña por año con 47 cargas a cuestas, sin pagar cosa alguna" (Ruiz 294). Hacia 1625 Pedro Daza Mejía ejercía aún el cargo de alcalde mayor de Santiago de las Atalayas, pero no sabemos hasta que año duró su gobierno.

\section{Crisis de las encomiendas y nuevas fundaciones a partir de Santiago (1625-1650)}

Los años 1630 trajeron los primeros cambios en la vida de los santiagueños. Gracias a las informaciones de la visita del licenciado Valcárcel, primer oidor en poner los pies en los llanos, se tomó la decisión de separar su territorio de los de Chita y Sogamoso, nombrándose corregidor independiente hacia 1637 (Ruiz 49). De esta manera se pretendía ejercer un control sobre las encomiendas recientemente fundadas y sobre los indios tributarios que según el informe habían pasado de 655 a 1104 en 1635 . Pero en realidad el nombramiento del corregidor no solucionó en manera alguna las irregularidades en el sistema de encomienda, sino que desplazo el equilibrio de poder entre las familias de los encomenderos más antiguos y los nuevos hacendados y estancieros que empezaban a enriquecerse con sus hatos y obrajes y que entraron a beneficiarse legalmente de la mano de obra que el nuevo sistema de concertados les permitía.

Hacia 1635 se transformó la alcaldía mayor de Santiago en gobernación que se concedió a Adrián Suárez de Vargas, primo de Diego Suárez de Vargas conquistador de achaguas, nieto de Diego Suárez Montañés cofundador de Santiago, y bisnieto de Juan de Vargas, gobernador del Dorado (ver gráficas). Adrián de Vargas había heredado de su padre la encomienda de Caibacoa y Gobero de indios achaguas. Sin embargo la ciudad había decaído hasta tal punto que ya para 1640 se hacia necesaria una nueva fundación. De acuerdo a un informe firmado ese mismo año por el gobernador, la ciudad de Santiago había sido reedificada y poblada con:

[...] vecinos donde asisten con sus mujeres, chinos y hacienda, la cual cada día va en crecimiento por ser temperamento muy a propósito y sano y hay iglesia decente para la celebración del culto divino y casas de cabildo y de vivienda competentes (AGI, SF 177, núm. 13, f. 6). 


\section{FRONTERAS}

de la historia

Era la cuarta vez que la ciudad se reedificaba. Es posible suponer que el despoblamiento se haya debido a une epidemia de tabardillo que fue general por esta época en el reino, aunque sería más factible pensar que la continua necesidad de soldados y los nuevos apuntamientos de indios que se recogían contribuyeron a dispersar la vecindad de la ciudad en estancias y obrajes ${ }^{6}$. Otra razón, acaso más contundente fue la aparición de nuevos núcleos de colonización. Durante los años 1630-1650 la fiebre de fundaciones se hizo más intensa. Los santiagueños emprendieron las de San Martín del Puerto (1633), Sófraga (163?) y Cravo (1649) tres puntos estratégicos que abrieron el campo a las conquistas de indios. Estas nuevas fundaciones corresponden a la crisis minera que debió sortear el presidente, marqués de Sófraga (Pacheco 324). Las encomiendas del altiplano se veían menguadas por el continuo envío de sus indios al trabajo de las minas y atendiendo a las continuas protestaciones de los encomenderos el presidente se vio en la necesidad de estimular las conquistas de indios macos o esclavos para mitigar la crisis.

La edificación de San Martín del Puerto fue encargada en 1633 por capitulación al encomendero Juan de Zárate, quien era por entonces uno de los hombres más ricos de Tunja ${ }^{7}$. El gobierno lo cedió a su teniente Antonio Hurtado de Tapia, vecino de Santiago, que sin duda atrajo a algunos vecinos pobres de la ciudad de Santiago ${ }^{8}$. San Martín fue edificada estratégicamente cerca del Ariari, punto de partida ideal para las conquistas de indios del Guaviare. La Gran Ciudad de Sófraga se capituló por estos mismos años por un cura de la ciudad de Santiago, que se hizo maestre de campo y conquistador del Dorado con título de gobernador y capitán general. El gobierno pasó luego a Martín de Mendoza y

\footnotetext{
${ }^{6}$ Germán Colmenares (43) sitúa esta epidemia en 1633.

${ }^{7}$ Zárate era encomendero de Tenza, Sutatenza, Ubeita, Chaine y Teguas y sus rentas sumaban más de 2.000 ducados. Vista su posición, muy pronto delegó su conquista en el capitán Juan Suárez Cardoso, quien había servido en Guayana y era práctico de indios de guerra (Ruiz 392).

${ }^{8}$ Así lo demuestra el testimonio del soldado Miguel de Ángel vecino de la ciudad de Santiago quien declaraba amargamente: "últimamente fui a la conquista pacificación y población de la ciudad de San Martin del Puerto donde acabé de consumir la poca hacienda que me quedaba y donde me he avecindado y en las unas y otras ocasiones expuse mi vida a mucho riesgo en las entradas y correrías que hice por ser los dichos indios caribes y hoy me hallo sumamente pobre y con obligación de mujer e hijos y no tener con qué poderlos sustentar, siendo así que la dicha mi mujer es hija legítima del capitán Pedro Núñez Pedroso uno de los primeros conquistadores y pobladores de la ciudad de Santiago de la Atalaya donde padeció infinitos trabajos y no ha sido premiado ni yo de los dichos servicios y de los que he hecho en las dichas ciudades donde he sido electo diferentes veces en alcalde ordinario y de la hermandad y otros de república que he ejercido con mucha aprobación de los vecinos" (AGI, SF 173, núm. 26, f. 50).
} 
Berrío, encomendero de Casanare, aunque el cura se quedó con el título de capitán general. En medio de dos poblaciones de Achaguas, el gobernador y su cura hicieron edificar un castillo a dos jornadas del Casanare y a tres del Meta desde donde hacían invasiones y entradas en busca de indios (Rivero 18). Hacia 1645 sucedía en el gobierno el santiagueño Alonso Sánchez Chamorro, quien con su hermano Juan organizó una gran entrada en Arauca para la pacificación de los indios giraras con 50 soldados y "muchos pertrechos de ganado vacuno y yeguas y mulas y caballos" (AGI $S F 173$, núm. 26, f. 94). La expedición fue un fracaso, pero en 1650 los Chamorro entraron a la ciudad de Tame y sacaron como esclavos más de 100 indios giraras que llevaron a Santafé, con el pretexto de haber participado en la muerte de un capitán (Rivero 83). Sánchez Chamorro pasó luego al gobierno de San Martín, donde fue muerto por los indios al cabo de seis años.

La ciudad de San José de Cravo, por su parte, fue edificada en 1649 por el gobernador de Santiago, Adrián Suárez de Vargas ${ }^{9}$. En ella se implantaron hatos y haciendas ganaderas que se convertiría más adelante en el nuevo punto estratégico para las entradas y conquistas en el Meta. En el siglo XVIII, los jesuitas desplazaron a los santiagueños y tomaron el control de esta región y de la hacienda de Tocaría, que junto con los pueblos de misiones fundados entre los ríos Cusiana y Guanapalo constituyeron un nuevo núcleo misional a partir de 1730 .

\section{Rescates y correrías (1601-1655)}

La institucionalización de las prácticas de cacería de indios corresponde, como vimos, a la crisis minera del Reino en los años 1630. Es, sin embargo, necesario que volvamos un poco atrás para entender mejor la evolución de un fenómeno que existió desde la época de los exploradores alemanes y de las expediciones doradistas de los Quesada y los Berrío. A principios del siglo XVII, durante el gobierno de Daza Mejía en Santiago, empezaron oficialmente las conquistas de indios en el río Meta, actividad que ocuparía a los santiagueños durante todo el curso del siglo XVII. Pese a que la ley exigía de los soldados la reducción de los indios a poblado y su consiguiente evangelización, las actividades de los santiagueños fueron en este sentido bastante irregulares. El nomadismo de los

\footnotetext{
9 "Fundé en la provincia de Cravo en un sitio que llaman Guanaca entre el río de Cravo y una quebrada Taquiramena, una ciudad que se intitula San Joseph de Cravo con diez y nueve hombres y sus familias donde hice iglesia, casas de cabildo y otras de vecinos y algunos de ellos casados que están asistentes en ella" (AGN, E 2, f. 6v).
} 


\section{FRONTERAS}

de la historia

indios y su calidad aguerrida fueron argumentos jurídicos que se invocaron para instaurar su esclavitud. A estas libertades contribuyó el aislamiento de la ciudad y la falta de control ejercido por la Corona.

Muchos indios se obtuvieron por rescate (compra o trueque), pues la esclavitud parece haber sido un fenómeno frecuente entre las tribus indígenas del Orinoco, que trocaban sus prisioneros por hachas y bujerías. Los achaguas, por ejemplo, se procuraron esclavos entre los quirruvas, mujirris, abanis y pizarvas del Gran Airico, que eran clanes enemigos (Rivero 47). Los europeos, aprovecharon ampliamente este contexto de guerras entre clanes para comprar indios 0 cambiarlos por cuchillos, hachas $\mathrm{u}$ otros utensilios. Walter Raleigh describe a finales del XVI cómo se realizaba este comercio entre los españoles y ciertas parcialidades de arawacos ${ }^{10}$. Los franceses también practicaron este comercio, pues en 1653 el padre jesuita Dionisio Mesland, que luego iría a Casanare, tuvo ocasión en Martinica de comprar dos indias de la Guayana a un francés que las había capturado en el río de Cupenam, cerca del Guarapiche ${ }^{11}$. Otro caso, censurado por los jesuitas Rivero y Cassani (324) y que viene de las annuas de Roma, explica cómo un soldado de la ciudad de San Juan de los Llanos, llamado Antonio Collado, se procuró por trueque un indio maco ${ }^{12}$. En 1692 existía aún este comercio, pues en una pesquisa contra los jesuitas se les acusaba de tener en su servicio "cincuenta macos todos bautizados y que los han habido de rescate" (AHN, CJ 123-1, f. 1). Dentro de los declarantes, Jacinto de Artajona, mayordomo de una de las haciendas, anotaba dentro de los inventarios

10 "De estos negocios — escribía Raleigh - sacan bastante ganancia los españoles, pues si compran por tres o cuatro hachas una doncella de doce o trece años, la revenden en Margarita de Indias Occidentales por cincuenta o cien pesos, o sea, por tantas coronas, constantes y sonantes" (Acosta 70).

11 'Une occasion assez favorable s'en presenta; un François ayant enlevé au mois d'Avril de l'an 1653 quelques Esclaves de la riviere de Coupenam dans la Guiane;\& les ayant menez à la Martinique, pour les vendre nous iugeâme que si nous les ramenions en leur pays nous y serions favorablement receus par leur moyen: si bien qu'ayant trouvé deux femmes de la nation des Galibis, nous les acheptâmes avec une petit fille qu'elle avoient de l'âge de deux ou trois ans" (Pelleprat 16).

${ }^{12}$ Annuas del provincial Juan Martínez Rubio de 1694 a 1698: "Cansose enfín el buen soldado de fingir bocablos y en contar disparates y hubo de atender como los indios al suyo a otro sermon que le hizo mucho más largo uno de ellos: de que quedó tan enterado como los bárbaros de lo que el les dijo. Pero no le faltó a su sermón la propina porque además de un gran vaso de bebida que llaman sucube le presentaron un maco. Llaman así a los cautivos que cogen unas naciones de otras enemigas, los cuales no hacen prisioneros de guerra sino esclavos y como de tales se sirven de ellos o los venden. Y aunque por este les había ofrecido otro español bastante precio no le habían querido vender" (ARSI, NRQ 13 II, f. 473). 
a "siete macos de rescate y cuatro chinas" (AHN, CJ 123-1, f. 13). En el mismo documento se acusaba también a los soldados del presidio de Carichana, cercano a las bocas del Meta, de tratar y contratar con los otomacos, "comprando y vendiendo macos achaguas por quiripa y otros géneros" (AHN, CJ 123-1, f. 38v).

Aunque los guahibos y chiricoas fueron llamados "indios de guerra" y considerados enemigos "naturales" de los españoles, existe evidencia suficiente que nos permite pensar que, contrariamente a lo que ocurrió con los achaguas, los colonos hicieron de ellos sus aliados de guerra en la captura de macos, reservándoles un tratamiento de favor. Así sucedió con los guahibos de Manaycas encomendados primero al gobernador Pedro Ordóñez y Vargas en 1670, enseguida a su hijo Francisco, sargento mayor de conquista de achaguas y a su muerte, en 1684, en tercera vida, a su nieto Pedro, maestre de campo y alcalde ordinario de Santiago (AGN, E 16, f. 249). En una denuncia contra este Pedro de Vargas era acusado de tolerar las costumbres nómadas de sus encomendados sin darles doctrina cristiana y de permitir sus entierros tradicionales. Aunque la información es tardía evidencia que ciertas parcialidades de guahibos mantuvieron relaciones pacificas prolongadas con los colonos. Es probable que estos indios hayan cooperado con los santiagueños en las capturas de macos, ya sea por su propia cuenta, engrosando la fila de la soldadesca española, o realizando un primer trabajo de asedio a las tribus que permitiera luego a los españoles consumar sus capturas. Según el padre Rivero, los guahibos vendían los achaguas, a trueque de caracoles, pues:

[...] la mercadería de más precio suelen ser muchos macos, hijos de otros indios, á quienes hacen guerra, ó que los hurtan ellos con su industria, sin usar de las armas. De éstas y semejantes cosas se aparecen cargados, y traen de muy lejos para vender á otros indios, y tal vez a los españoles (150).

Es probable que estas guerras contra los achaguas de que habla largamente Rivero en su Historia hayan sido toleradas, propiciadas o incitadas por los colonos, al modo en que los holandeses y franceses propiciaron las suyas a favor de los caribes del Orinoco. Esto ha debido ser motivo de conflictos entre los santiagueños y lo jesuitas desde la instauración de sus misiones en 1659. Los padres defendieron a los achaguas de estas invasiones, razón por la cual muchos vinieron a poblarse en las misiones desde las áreas al norte del Meta (Rivero 161).

Otro medio frecuente para hacerse a los indios eran las famosas entradas o correrías para sacarlos manu militari de sus pueblos y caseríos o para someter y 


\section{FRONTERAS}

de la fistoria

castigar los que habían huido ${ }^{13}$. Una vez bautizados y reducidos a "poblazones", sus continuas ausencias, que hacían parte de su modo tradicional de vida, eran interpretadas como traición al rey, y a este título eran perseguidos y castigados con duros trabajos. Para organizar entrada era necesario obtener el permiso del gobernador o alcalde por cierta cantidad de dinero simulado como título religioso, o expedición punitiva, pues las leyes de Indias prohibieron y restringieron desde muy temprano este tipo de actividad. La Ordenanza 67 de Felipe III, del 10 de octubre de 1618, reglamentaba la forma de hacerse las entradas prohibiendo a los gobernadores, tenientes y alcaldes ordinarios "[...] enviar gente armada contra Indios, á título de que se reduzcan, ó vengan á hacer mita, ni con otro pretexto, pena de privación de oficio, y de 2.000 pesos para nuestra Cámara" (Recopilación lib. III, tít. IV, ley X).

Con todo, la misma ley añadía:

[...] pero bien permitimos, que si algunos Indios hizieren daño á Españoles, ó á Indios de paz, en sus personas, ó haziendas, puedan luego, ó hasta tres meses enviar personas con armas á que los castiguen, ó traigan presos, con que en los presos no se execute pena en el campo, si la dilacion no causare daño irreparable, $\mathrm{y}$ en ninguna forma se puedan repartir los Indios por piezas, como en algunas Provincias se ha hecho sin nuestra orden y voluntad, pena de mil pesos al que contrario hiziere (Recopilación lib. III, tít. IV, ley XI).

Las capturas eran lideradas por un cabo o capitán, muchas veces por el alcalde o gobernador en persona. Si los soldados eran españoles, la captura era para la doctrina a la que pertenecían y recibían una remuneración o "reparto" de los que atrapaban. Cuando los capturadores eran mestizos o indios "rentados", se les pagaba por su participación diaria, además del precio por los indios que también capturaran. Los hombres se amarraban con lazos al cuello y por lo general las mujeres y los niños iban sueltos.

\footnotetext{
${ }^{13}$ En 1620 el arzobispo Arias de Ugarte señalaba la esclavitud de los indios del llano en su visita: "Han acostumbrado españoles mestizos y mulatos a entrar a caza de estos indios con autoridad de los gobernadores con ocasión de que son salteadores y que los traen para hacerlos cristianos y sin constar que hayan antes dado la paz ni que sean salteadores más de por la voz general que echan para justificar sus crueldades los cautivan y sacan a estas provincias, matando a los que se defienden apartando los padres de los hijos, las mujeres de sus maridos, quitándoles la miseria que tienen que aunque es todo poco privándoles de la libertad es de gran consideracion de los que sacan se sirven como esclavos (si ya no es que los venden como se publica)" (AGI, $S F$ 79-2-20; FPC 52).
} 
La primera entrada de que tenemos noticia de parte de los santiagueños fue hecha en 1601 por el justicia mayor de Santiago, el capitán Diego Suárez de Vargas, tercero de su nombre, quien pasando a la otra banda del río Meta descubrió el potencial de indios achaguas de la provincia que entonces llamó de Quenaven y Airico (Vichada Guaviare) (AGI, $S F$ 177-11, f. 5). Es poco lo que sabemos sobre el uso que de los indios de estas capturas hicieron los santiagueños. En 1602 se apuntaban en Diego Suárez de Vargas, 58 que habían sido recogidos y fundados en los pueblo de Cupiagua y Cavita, y a su hermano Francisco, 77 achaguas y teguas que se fundaron en los pueblos de Caibacoa y Gobero (Ruiz 365) ${ }^{14}$. Aparte de estas cuatro poblaciones, los archivos se refieren solamente a parcialidades frecuentemente bautizadas de acuerdo al apellido de sus caciques o del nombre de sus naciones ${ }^{15}$. Para el resto, aunque estas tribus figuran frecuentemente anotadas en encomienda, de ellas no aparece población ni doctrina. Es el caso de las encomiendas de los santiagueños Diego de la Fuente, Diego García, Pedro Hurtado, Antonio Hurtado de Tapia y Juan Sánchez Chamorro. Esta información parece confirmar los abusos y comercios que se hacían con los achaguas del llano, que eran parte de la categoría de indios de media paz, y no de suma paz, como fue el caso de los indios del altiplano. El padre Rivero nos cuenta varios casos de estas correrías de los santiagueños entre las cuales la más dramática parece haber sido la del capitán Alonso Jiménez quien en 1606 descubrió en el Meta más de 4.000 achaguas. Jiménez fundó allí un pueblo y obligó a los indios a levantar una iglesia. Una vez aprendieron a rezar en ella, los encerró y capturo "poniéndolos en argollas y colleras" para llevarlos a trabajar en las minas (24).

Otra entrada tuvo lugar en 1609 a cargo del capitán Cristóbal López Navarro, más tarde teniente del gobernador de San Martín, y del caudillo Lázaro de la Cruz (AGI, $S F$ 177-13, f. 14v.). Navarro entró de nuevo en busca de indios en 1609 y en 1625 (AGI, $S F$ 177-13, f. 15). Otra famosa expedición fue la organizada en 1635 por el gobernador Adrián Suárez de Vargas, quien pasó a la otra banda del Meta con 37 soldados y descubrió la provincia de Anayare

\footnotetext{
${ }^{14}$ Las cifras oficiales, que corresponden a indios útiles o susceptibles de tributo, son a mi modo de ver poco significativas y permiten difícilmente hacerse una idea de la realidad, pues no toman en cuenta ni los tratos y contratos de macos, ni los indios rebeldes con quienes, como veremos, los santiagueños comerciaban, ni las mujeres, ni los niños, que eran también forzados al trabajo de obraje.

${ }^{15}$ Para 1588 las únicas parcialidades que parecen corresponder a un asentamiento son las de Caibacoa y Gobero y a partir de 1602 las de Cupiagua, Cavita, Chámeza y Cusiana. En ese año se anotaron los siguientes grupos étnicos: caquetios, achaguas, teguas, guesbas, guascamas, yanzuas, vijuas, sutagaes. Véase Rueda (56).
} 


\section{FRONTERAS}

de la historia

poblada de las parcialidades de achaguas de Dumagua, Pupure, Moco, Charrucaben, Guaroca, Dauma y Caragataba ${ }^{16}$. Según las informaciones y actas levantadas, el gobernador anotó todos los indios a sus soldados y remitió al marqués de Sófraga para las minas de las Lajas "quince gandules y diez indias con dos crías guahibas que hicieron resistencia a los que los llevaban y maltrataron" (AGI, $S F$ 171-68, f. 5v.). El envío debió ser muy superior, pues el sargento Bernardo Sánchez Muñoz, provincial de la santa hermandad de Santiago y cabo de la escolta, revela en un informe tener a cargo para dicha conducción a más de 20 soldados (AGI, $S F 177-13$, f. 14v.). Es muy posible que esta entrada sea la misma a la que se refiere Rivero al hablar del maestre de campo Antonio Hurtado de Tapia, quien regresó a Santiago "con el pillaje de más de trescientos veinte presos" $(30)^{17}$.

Un ejemplo concreto de estas correrías fue la organizada por Francisco Suárez de Vargas, uno de los hijos del gobernador de Santiago. En abril 1655 se declaraba oficialmente el alzamiento y huida de los caciques achaguas Quenaven y Curitaquen quienes:

[...] sin más ocasión de la de su natural vicioso, se han retirado a las provincias del río abajo de Meta, Vichada y Arico y Bocas de Casanare negando la obediencia que a su majestad tenían dada metiéndose entre indios infieles y de guerra de dichas provincias (AGI, SF 173-27, f. 12).

Se justificaba la entrada, además, por la agresión que habían hecho a su doctrinero, el bachiller Antonio de Gálvez:

[...] porque semejante delito tenga castigo ejemplar y los demás bárbaros infieles y los alzados se reduzcan [...] mando [....] con la brevedad posible según se requiere el caso antes que los dichos indios sientan el que van en su demanda, recojan con toda maña los hombres y soldados que tienen prevenidos y todas las más canoas que pudieren y haciendo que van por diferente vía den en la población que tienen dichos indios sin dar a entender van a castigo de el delito

\footnotetext{
${ }^{16}$ Según la capitulación de gobierno, Adrián Suárez de Vargas, tenía facultad para apuntarse "mil indios de demora con sus chusmas y familias y los demas a apuntarlos a los vecinos y soldados" a quienes se darían los tributos por tres vidas al ser indios de descubrimiento (AGI, SF 171-68, f. $5)$.

${ }^{17}$ Hurtado de Tapia había empezado como provincial de la santa hermandad en Santiago, donde fue ascendido hasta el cargo de teniente del gobernador Adrián de Vargas. Su hijo Faustino de Tapia sería, a su vez, teniente del futuro gobernador de Santiago. El gobernador Pedro Ordóñez le había adjudicado los 21 indios de la encomienda de Aguamena y Guesba que se encontraba vacante (AGI, $S F$ 171-68, ff. 2v-3).
} 
atroz cometido con palabras halagüeñas y medios más suaves los reduzcan todos (AGI, SF 173-27, f. 19v).

La expedición partió del sitio de Sabana Alta el día 27 de septiembre de 1655. Desde el río de Upía salieron con 19 canoas y sus indios bogas los 57 soldados que componían la infantería con "los bagajes y los pertrechos de guerra para seguir por dicho río a dar en el de Meta" (AGI, $S F$ 173-27, f. 20). A cinco días de navegación, llegaron a un paraje donde se descubrieron:

[...] unos fuegos aunque muy distantes que las guías dijeron ser naciones de achaguas indios de guerra [...] y entre ellos muchos que han sido encomendados [...] que favorecidos de los tales indios de guerra viven en tal ellos a su albedrío y vicios y de la otra banda de dicho río dichos humos las dichas guías dijeron ser guahibas salteadores (AGI, $S F$ 173-27, f. 25).

Para no ser sentidos determinaron:

[...] se vaya con todo silencio y las canoas y embarcaciones en que van los soldados, bagaje y demás pertrechos de guerra vayan juntos a una vista y con todo cuidado y silencio y que se despache delante descubriendo y reconociendo, una canoa con infantería para los lances que se pudieren ofrecer (AGI, $S F$ 17327, f. $24 v$.$) .$

Al día siguiente se descargaron las canoas en un paraje abrigado donde se instalaron los reales, "dejando guarda y custodia con los bagajes y pertrechos de guerra". La infantería continuó con todo orden y silencio, "nadando en el barro por encima de la rodilla" hasta las doce de la noche, en que se divisó una población con seis caneyes. "Sin más dilación se repartió la infantería en tercios" y se cercaron los caneyes "con todo silencio tiento y suavidad y los mejores medios de paz" y "se vencieron y prendieron y estándolo se contaron y hallaron setenta y ocho piezas chicas y grandes". Habiendo dejado los prisioneros con nueve soldados, la tropa partió nuevamente a la captura de otro pueblo llamado Carvata, que según les avisaban se encontraba a seis leguas de allí. A las cuatro de la mañana los soldados atacaron otros dos caneyes "con toda vigilancia halagos amorosos y medios suaves de paz" y prendieron "treinta piezas chicas y grandes, gandules y su chusma" (AGI, $S F 173-27$, f. 26-27v.). Estos prisioneros señalaban venir huyendo de la otra banda del Meta donde los guahibos les hacían cruentas guerras e informaban de la existencia de otros pueblos más abajo de las bocas del río Pauto. La custodia de los prisioneros se confió a diez soldados con encargo de emprender el regreso a pie, por las riveras del Meta arriba. Al cabo de cinco días ya se habían capturado 265 indios 


\section{FRONTERAS}

de la fistoria

más, de las cuales ninguno era realmente fugitivo. El método empleado fue siempre el mismo: instalación de un real como campo de guardia para los prisioneros y ataque sorpresivo a los caneyes indígenas durante la noche.

El 11 de octubre a las cinco de la tarde ya estaba toda la infantería recogida en el puesto de Curirupapo desde donde se enviaron a un sitio llamado Pueblo Grande dos indios ladinos para exhortar el regreso de los achaguas que se habían fugado "para que en su lenguaje con amorosos halagos y medios de paz citen, llamen y exhorten y requieran a todos los dichos indios parezcan y vengan ante nos". Al cabo de tres días se presentó el cacique Chamaraguaca con sus 44 sujetos que "de muy buena gana [venían] con toda su gente para salir a poblarse en la ciudad de Santiago" y más tarde se presentaron los caciques de los Cumataberrenay, Chaverrenay y Maraverrenay con 48 indios que "acosados de guerras, [venían] para salirse a poblar en la parte y lugar que les sea señalado" (AGI, SF 173-27, ff. 35-36v.).

Estos 100 indios fueron despojados de sus armas y conducidos como prisioneros con el resto de la tropa de achaguas, que sumaba en total casi 500 . El 16 de octubre los indios pasaron en canoa a la otra banda del Meta desde donde caminaron escoltados por los soldados hasta las bocas del río de Crabo y de allí río arriba hasta el pueblo de Tocarimena, adonde llegaron el 6 de noviembre de 1655, después de 21 días de camino. El 7 de noviembre, el capitán Francisco Suárez de Vargas repartía los indios entre los soldados. Para él se reservó 78 piezas y a su capitán Juan Fernández Mariño entregó 65, junto con 18 rebeldes que se le entregaron en depósito y que pertenecían a Alonso Sánchez Chamorro ${ }^{18}$. En importancia siguieron 42 piezas para Esteban Sánchez Chamorro, 39 para Martín Fernández, 34 para Alonso Pérez, 27 para Hernando Mejía, 21 para Diego de Tena, 13 para Gabriel López de Alarcón y 7 para Juan de Tapia ${ }^{19}$. Las dos cabezas de la expedición y estos 7 soldados se repartieron

\footnotetext{
${ }^{18}$ Los 78 indios quenaven con su cacique Cariguay se mandaron poner en el sitio de Iguamena y doctrinar por el padre Francisco de Luna Vallezilla, cura de la ciudad de San José de Pore. El cacique Mauritaquenay y sus 65 sujetos de nación curitaquen fueron dados al capitan Juan Fernandez Mariño (AGI, SF 173-27, f. 43).

${ }^{19}$ Los 42 achaguas de la nación Unibinay sin sujeción a español alguno fueron depositadas en Esteban Sánchez Chamorro. Las 39 piezas del cacique Duque también sin sujeción pasaron al sargento Martín Fernández "con cargo de hacer vecindad en dicha ciudad de San Joseph de Cravo y de dar a dichos indios doctrina". Alonso Pérez de Guzmán por su parte recibió las 34 piezas del cacique Baguamina, Hernando Mejia 27 chaverrenayes, Diego de tena 13 quenavenes y " 8 indios gandules sin mujeres ni cabeza de cacique", Gabriel López de Alarcón 13 cagivanayben y Juan de Tapia 7 cagivanayvenes (AGI, SF 173-27, ff. 44-46).
} 
344 indios, mientras los 26 soldados de mayor merito recibieron cada uno una pieza "de la chusma de muchachos y chinas huérfanos sin padre ni madre" y "con cargo de que las tales piezas que se les dieren sean para tan solo el servicio de sus casas y que no puedan enajenarlas" (AGI, $S F 173-27$, ff. 50v.).

Seis meses después, cuando el gobernador Pedro Ordóñez y Vargas bajó a los llanos de su encomienda de Tota a describir y asentar los indios, se anotaron legalmente 162, de los cuales 61 se consideraban perdidos ${ }^{20}$. En realidad sólo había 101 indios descritos para repartir en encomienda de los 475 recogidos inicialmente. De este último número 102 fueron indios fugitivos que debieron integrar sus puestos de encomienda lo que en teoría disminuía la cifra real de reparto a 373 indios. Si 86 se escaparon y 25 fueron repartidos para el servicio domestico de los soldados, la cifra real de reparto sería de 262 indios, pero de acuerdo con las actas los indios descritos y anotados para reparto de encomienda fueron sólo 101. ¿Qué ocurrió con las otros 161? ¿Serían acaso estas las famosas piezas vendidas o repartidas ilegalmente?

\section{Primeras noticias de asiento en la tierra}

Según un informe de 1640, la ciudad de Santiago y su provincia pagaba 1.395 pesos y 5 reales de diezmos, fabricaba 12.000 varas de lienzo de algodón por año, su ganado de cerda pasaba de las 6.000 cabezas y era vendido en todo el reino, mientras el vacuno ascendía a 5.000 cabezas que abastecían la ciudad de Tunja y cada año se sacaban más de 2.000 arrobas de pescado. Para la segunda mitad del siglo XVII la ciudad de Santiago debió ser aún más próspera. En 1663 un clérigo de nombre José de Vargas y Alarcón manifestaba la urgencia de aumentar el número de habitantes, pues declaraba que la ciudad no tenía más de 20 vecinos (AGI, $S F$ 173-26, f. 75). Si tenemos en cuenta la noción restringida de la palabra vecino, puede pensarse que la ciudad y su territorio contaban en promedio unas 200 personas, probablemente diseminadas en los alrededores cerca de sus indios ${ }^{21}$. Juan Flores de Ocáriz cita la ciudad de Santiago como

\footnotetext{
${ }^{20}$ De la parcialidad del cacique Pedro Duque se describieron 25 indios y las doce piezas faltantes dice el auto que "constó haberse huido los dichos indios". De la parcialidad del cacique Ricaguey con 40 indios descritos se fundo un puesto llamado Yuguamena y eran cuidados por el mayordomo de la hacienda de caibacoa que fue de Adrián de Vargas. 15 indios huyeron de este puesto. De los indios depositados en Esteban Sánchez Chamorro cacique Diego Uribinay se describieron 36 indios. Los 34 indios del cacique Baguayuna huyeron todos pues Alonso Pérez de Guzmán había enfermado (AGI, SF 173-27, ff. 51-55).

21 Según las relaciones geográficas la ciudad de Tunja tenía 300 vecinos, pero según la historiadora Cortés Alonso, tomando en cuenta la noción de cabeza de familia que el concepto
} 


\section{FRONTERAS}

de la historia

cabeza de uno de las doce gobiernos de capitulaciones existentes en el Nuevo Reino $^{22}$ y cuando los santiagueños recibieron al visitador eclesiástico Onofre de Baños y Sotomayor en 1678, su gente era entonces "la más de ella noble y de caudal", tenía ya iglesia bien edificada "de tapias de muy bien cañón en madera y cubiertas de nuevo y bien alhajadas de ornamentos para la celebración del culto divino, y en el altar mayor un cielo de madera, con caída de tafetán para su aseo y limpieza", un hospital, una plaza de armas "de muy buena planta", casas de cabildo, cárcel, edificios para despacho y 30 casas "todo de buen arte y seguridad, que parece antes no los había, todo muy en política, y todas las casas de la ciudad son nuevas, blanqueadas las más con curiosidad" (Ganuza 175).

La familia Sánchez Chamorro es un ejemplo de la prosperidad que por los años 1650-1670 vivieron los santiagueños ${ }^{23}$. Además de tener reputación de cazadores de indios, los Sánchez eran ricos y poderosos hacendados de Santiago, y se ocupaban no solamente de obrajes de algodón y de estancias de ganado, sino también de pesquerías. Además, desde 1660 Juan Sánchez Chamorro era el corregidor de toda la provincia.

No nos ha sido posible averiguar de que época datan los primeros obrajes de algodón en Santiago, aunque sabemos que en Chita, Morcote, Tamara, Chámeza y Labranzagrande se desarrollaron junto con las doctrinas de agustinos en algunos casos desde 1585 (Langebaek; Rausch 111). En Labranzagrande y Morcote, la tradición en la producción y comercio del algodón remontaba al periodo prehispánico, cuando estos pueblos estaban sujetos al cacique Sogamoso. Considerando los abusos que por todas partes se cometían haciendo

vecino implicaba en la época y el hecho de que un plano de 1623 refieren 399 casas, calcula la población total en unas 3.000 personas $(159,193)$. Según estas mismas relaciones sus habitantes encomenderos vivían la mayor parte del año en sus estancias y haciendas "por no poder sustentarse de ordinario en la ciudad" (Mörner 245).

${ }^{22}$ De estos doce, seis correspondían al territorio llanero: San Juan de los Llanos, Medina de la Torre, el Caguán, Arauca y Apure.

${ }^{23}$ El soldado Sánchez Chamorro fue uno de los primeros pobladores de Santiago, donde en 1588 se le repartieron los indios de nación Yanzua y en 1596 junto con su familiar Pedro Sánchez se les encomendaron parcialidades de indios tuas. Posteriormente fue alcalde ordinario y ascendió a teniente de Pedro Daza Mejía. Sus dos hijos fueron Alonso y Juan Sánchez Chamorro. El primero fue gobernador de Tame y Arauca por 1645 y luego gobernador de San Martín donde lo mataron. Su hermano Juan fue maestre de campo, acompañó a su hermano en Arauca y San Martín y luego fue nombrado corregidor de los llanos después de 1650. Este último tuvo tres hijos entre los cuales se conoce el mayor Esteban Sánchez Chamorro por su reputación de cazador de indios, aunque según Rivero los otros dos hermanos también la tenían. Véase Rivero (212). 
trabajar a mujeres y niños sin remuneración alguna, los obrajes de algodón se prohibieron generalmente en todas las Indias por cédula del Consejo de $1601^{24}$. La prohibición parece no haber surtido ningún efecto en los llanos, donde, gracias a la crónica del padre Rivero, sabemos que los santiagueños beneficiaron en abundancia el algodón haciendo trabajar a los achaguas ${ }^{25}$. También encontramos prueba de estos obrajes en los archivos. En 1659, los indios se quejaban de Alonso Sánchez Chamorro en memorial ante el protector general de indios:

[...] pues los llevan como esclavos, y les quitan sus mujeres, y encierran para que hilen... y que un hermano del gobernador Alonso Sánchez Chamorro, es el que solo hurta estos indios para un sobrino suyo o para el, poniéndolos en cautiverio como están los demás, que lo han hecho desde el tiempo de sus abuelos (AGN, CI 25, f. 739).

No es pues de extrañar que los santiagueños sacaran ya para 164012.000 varas de lienzo de algodón por año, cantidad que era consecuente si tenemos en cuenta que en 1610 los ocho obrajes de la provincia de Tunja producían cada año 15.000 varas de sayal (Mörner 246).

Para los hatos y estancias, al igual que en el caso de las minas, la ley era más permisiva en el uso de los indios pues admitía su repartimiento forzado y autorizaba el servicio personal para el pastoreo (Solórzano 1: 307). Cada hato debía tener 2.000 cabezas de ganado, una caza de piedra y una legua en contorno y la cantidad de ganado se limitaba a tres asientos que no superaran las 10.000 cabezas (Recopilación lib. IV, tít. XVII, ley V). Cada indio pastor debía tener a su cargo no más de 800 cabezas. Hacia 1640 uno de los hatos más ricos

\footnotetext{
${ }^{24}$ Dentro de los argumentos a favor de los obrajes de algodón, Solórzano Pereyra señala: “Añaden a esto que la ocupación es tal que pueden y suelen ayudar en ella muchachos de nueve o diez años, y éstos comienzan desde entonces a ganar salarios o jornales, aunque hasta los dieciocho no entran a tributar" (1: 316, 319). Véase Recopilación (lib. VI, tít. XII, lib. V, tít. XIX, lib. IV, tít. XXVI, ley II). "Otrosí, porque he sido informado, que el trabajo que los indios han padecido, y padecen en los obrajes de paños, é ingenios de azúcar es muy grande, y excesivo, y contrario á su salud, y causa de que se hayan consumido, y acabado en él muchos: prohíbo, y expresamente defiendo, y mando, que de aquí en adelante en ninguna Provincia ni parte de esos Reynos puedan trabajar, ni trabajen los Indios en los dichos obrajes de paños de Españoles, ni en los ingenios de azúcar, lino, lana, seda o algodon, ni en cosa semejante, aunque los Españoles tengan los dichos obrajes, é ingenios en compañia de los mismos Indios, o en otra cualquiera manera".

25 "Para eso, escribe el misionero, tenían ramadas muchas y muy capaces, y en ellas, como si fueran cárceles ó mazmorras, de Berbería, tenían encerradas á estas gentes, atareadas todo el día en desmotar e hilar el algodón, más oprimidos y sujetos que si fueran esclavos" (32).
} 


\section{FRONTERAS}

de la fistoria

Vol.12 / 2007

de Santiago pertenecía a los hermanos Juan y Alonso Sánchez Chamorro ${ }^{26}$. Los nombres de estos dos santiagueños están muy relacionados con el principio de la famosa hacienda jesuita de Caribabare tan reputada y codiciada durante el siglo XVIII. Su origen data de 1645, cuando los hermanos Sánchez Chamorro salieron de Santiago a poblar la provincia de Tame:

[...] donde llevaron cantidad de ganado vacuno, yeguos, mulos y caballos para el sustento y avío de los soldados que llevaron con otros muchos pertrechos necesarios y todo esto a su costa y misión (AGI, $S F 26$, f. 91).

Más tarde en 1661, por orden del presidente Manrique, el maestre de campo Juan Sánchez Chamorro, corregidor de los llanos, adjudicó a la Compañía de Jesús las tierras vacas que iban desde el río Casanare hasta el sitio llamado de Tunapuna que fueron los primeros predios de la hacienda de Caribabare (AGN, $T B$ 21, f. 844). Esta merced fue confirmada en 1662 por el presidente Diego de Egues y Beaumont decretando el derecho de poseer 3 estancias de ganado mayor de la medida antigua de la ciudad de Tocayma (Pérez 68). Aunque los jesuitas conocieron los excesos de los Sánchez Chamorro, la alianza con esta familia era indispensable para el desarrollo de sus haciendas y misiones, pues el corregidor, era uno de los grandes terratenientes de Santiago. Prueba de la existencia de lazos de amistad entre los misioneros y la familia Sánchez Chamorro es el hecho de que la Compañía de Jesús se haya prestado para asegurar la representación de los derechos personales de Sánchez Chamorro ante la Audiencia en Santafé y el Consejo de Indias en Madrid ${ }^{27}$. Es posible imaginar a cambio de qué favores se comprometieron los jesuitas a convertirse en sus abogados.

\footnotetext{
${ }^{26}$ Un testigo declaraba en efecto a su propósito: "que conoció a Alonso Sánchez Chamorro gobernador de las provincias de Tame y Arauca y que antes que fuese gobernador los conoció al dicho Alonso Sánchez Chamorro y al dicho Juan Sánchez Chamorro en la jurisdicción de Santiago de la Atalaya con muchas haciendas de ganados vacunos, yeguas, mulas y caballos y esclavos" (AGI, $S F$ 173-26, f. 91v).

${ }^{27}$ El documento aparece fechado en Pauto en 1663. Un año después de la autorización de constituir los hatos, Juan Sánchez Chamorro daba poder general de actuar en su nombre al padre jesuita Diego de Molina para que éste pudiera "parecer ante cualquiera tribunales asi eclesiasticos como seculares y oponerse en cuales quiera oposiciones que a mi derecho convengan dando y haciendo demostración de mis méritos y servicios y de los de mis padres, alegándolos y representándolos como yo mesmo lo pudiera hacer y para todo aquello que me convenga y se me ofreciere y pueda ofrecer en todos grados y instancias, así en la ciudad de Santafé y en todas demás ciudades, villas y lugares de su majestad, así en este reino como en los reinos de España" (AGI, $S F$ 173-26, f. 99).
} 
Sobre las pesquerías sabemos que eran hechas por los achaguas, que según Rivero habían aprendido de los sálivas la técnica de pesca con cuna o barbasco (8). Muchas eran hechas para beneficiar a sus encomenderos o misioneros. Así, en 1660 el gobernador de San Martín prestaba a este efecto cierta cantidad de indios piezas a Esteban Sánchez Chamorro (AGN, CI 25, f. 738). Un testimonio más tardío (1690) refiere cómo era cocinado y salado el pescado para llevarlo luego a Tunja y Santafé y cómo los indios eran pagados por ciertos particulares durante los dos meses que duraba la pesca valiéndose "del corregidor y de los padres (jesuitas) para que les den indios de aquel pueblo y otros de la misión de los llanos para ir a pescar" (AGI $S F 249$, f. 62v.).

\section{Convivencia entre santiagueños y misioneros (1655-1699)}

Durante el gobierno de los hermanos Suárez de Vargas (1640-1675) ocurrieron cambios importantes debido a la llegada de los misioneros dominicos, franciscanos, recoletos y jesuitas, que establecieron sus nuevas misiones por órdenes del gobierno superior. Nos referiremos aquí particularmente a los recoletos y jesuitas que fueron los vecinos más inmediatos de los santiagueños.

Los padres agustinos recoletos (candelarios) fueron los misioneros más próximos a la vecindad de los santiagueños y fundaron sus pueblos entre los ríos Upía y Cusiana desde 1662. Uno de sus misioneros era el santiagueño fray Cristóbal de Alarcón de San José, quien después de enviudar había recibido el hábito de hermano coadjutor. Este fraile no era otro que el capitán Cristóbal López Navarro, nieto de Bartolomé de Alarcón y de Mariana Daza, quien desde 1609 había participado en todas las correrías hechas por los santiagueños. En 1662, casi con 80 años de edad, continuaba en la conquista de indios como misionero candelario y había fundado sobre la margen izquierda del río Cusiana la doctrina de Sabana Alta, también llamada San Guillermo de Taburamena. Aunque según el padre Ganuza, esta fundación se hizo en 1662 con los 200 indios "que andaban por los campos sin sujeción de la parte de acá del río Meta" (181) y se pusieron en la corona real, la cuestión es poco clara pues, de un lado, los documentos hacen mención de la existencia de esta doctrina desde 1630 y del otro, los dos hijos de fray Cristóbal, Juan y Gabriel López de Alarcón aparecen en 1667 con encomiendas particulares de achaguas agregados a esta misma doctrina ${ }^{28}$. Dice Ganuza que en 1664 nuestro fraile partió

\footnotetext{
${ }^{28}$ Gabriel López de Alarcón sirvió en la reducción de los achaguas que se poblaron en la Sabana Alta "más habrá de treinta años", lo que significa que Sabana Alta se pobló en el decenio de 1630, no de 1660, como señala Ganuza. Estos indios estaban reducidos y agregados en el pueblo de San Guillermo de Taburamena y según la certificación sólo quedaban 17 pues la mayoría habían huido
} 


\section{FRONTERAS}

de la historia

nuevamente "en busca de mies para la misión" a la otra banda del Meta en compañía de su hijo Juan de Alarcón y de ocho indio. De su expedición se trajeron 260 indios con los que se fundó hacia 1665 el pueblo de La Concepción de Iximena en la ciénaga del caño Dumagua. Esta doctrina fue confiada al candelario fray Juan de San Buenaventura, pero para el año 1669 no quedaban más que $60^{29}$. Pese a ello, el fraile y sus hijos parecen haber puesto empeño en hacer prosperar este pueblo organizando nueva expedición para castigar a los prófugos y fundando allí un hato llamado Santa Rosalía de Dumagua ${ }^{30}$.

La misión de los padres recoletos debió prosperar mucho durante el nombramiento de un Alarcón en el gobierno de la provincia, pues para 1679 se mencionan más de 1.500 almas recogidas (Ganuza 200). Bartolomé de Alarcón gobernó, en efecto, Santiago desde 1671 hasta 1684, cuando lo sucedió Pedro Daza y Espeleta, que era el quinto de su nombre. El nuevo gobernador parece haber sido más favorable a los jesuitas que a los recoletos, pues desde la salida de Alarcón hubo problemas con las misiones recoletas. Los candelarios fueron denunciados por no hacer su trabajo de misión. Es poco lo que sabemos sobre el posterior desarrollo de la misión recoleta. Es probable que los pueblos de Tauramena e Iximena hayan subsistido en sus antiguos asientos durante todo el curso del siglo XVIII, pero es necesario ahondar en la investigación para corroborar la existencia de nuevas conquistas y fundaciones, pues la información contenida en los anales de los recoletos es a este respecto bastante pobre. A partir de la expulsión de los jesuitas en 1767, los recoletos heredaron de éstos las misiones del Meta, que conservaron hasta mediados del siglo XIX, cuando desaparecieron arruinadas por las guerras civiles y las leyes de desamortización. Tampoco es mucho lo que sabemos sobre las relaciones entre recoletos y santiagueños, pero visto el largo periodo en que los misioneros permanecieron en la región, es posible suponer que las prácticas misionales se

a San Martín y se encontraban ausentes. Véase la confirmación de una encomienda de indios achaguas de apellido Casibanay y Chaberrenay que el gobernador Pedro Ordóñez y Vargas le había entregado por dos vidas a Gabriel López de Alarcón (AGN, E 12, ff. 263-267 y 922).

\footnotetext{
${ }^{29}$ Según fray Pedro Fabo citado por Ganuza, este pueblo se encontraba en un caño cerca de San Pedro de Upía "cerca del cual existe un hato o hacienda llamada Santa Rosalía de Dumagua, parece ser el pueblo de Barroblanco, que hoy llaman Tauramena" (189).

${ }^{30}$ El mismo año de 1669 se organizaba expedición punitiva para volver a sacarlos. El cura de Santiago Francisco de Igola y Sotomayor certifica esta huida: "doy a esta certificación a efecto de que dicho maestre de campo solicite en competente tribunal el que den orden para volver a traer y sacar dichos gentiles y que para ello se dé avío" (Ganuza 196).
} 
hayan desarrollado cuando no en estrecha colaboración con los colonos si por lo menos bajo un amplio régimen de tolerancia.

Los jesuitas se asentaron en los llanos de Casanare desde el río Pauto hasta la región selvática del Meta y el Orinoco. Su llegada fue mal vista por los santiagueños, pues los misioneros entraban como representantes de la Corona a concurrir con las encomiendas privadas. El primer conflicto ocurrió hacia 1655, cuando el jesuita francés Antonio de Monteverde, que por entonces doctrinaba los guahibos, tuvo dificultades con el gobernador Adrián Suárez de Vargas por conflictos de ubicación entre las ciudades de españoles que éste quería fundar y las reducciones de guahibos y chiricoas que el misionero había emprendido. El padre sorteó las dificultades recordándole las obligaciones legales que debía tener para fundar y que al parecer no cumplía. Nuevamente en 1660 los jesuitas tuvieron problemas con el gobernador Pedro Ordóñez y Vargas, hermano del anterior, quien pretendía llevarse a Santiago cierta parcialidad de achaguas que los padres habían empezado a doctrinar en San Salvador del Puerto. Fue preciso al jesuita Alonso de Neira aplacarle los ánimos recordándole seguramente el poderoso aliado que los jesuitas tenían en el gobierno superior. En efecto, por intermedio de su prelado, los jesuitas dieron parte de sus abusos al presidente Diego Egües y Beaumont, quien era muy devoto de la orden. Mediante cédula del 18 de julio de 1662, Egües prohibió a los gobernadores emprender ellos mismos entradas, o expediciones de soldados, o permitir a otros hacerlo, para asegurar así el trabajo de los misioneros (Pacheco, "La consolidación" 656). Ordenó, además, colocar reproducciones del escudo del Rey en todas las encomiendas reales para intimidar a los colonos que abusaban de los indios (Rausch 110). Al año siguiente, 1663, declaró bacas por vicios en la composición las encomiendas de Chámeza y Cusiana pertenecientes a Juan Daza Pérez Godoy, hijo de Pedro Daza Mejía (AGI, $S F$ 173-26, f. 75). Del mismo modo, mantuvo separadas las encomiendas de Pesca y Bombasa, que vacaron por muerte de Pedro Daza y Olarte y las encomendó en Juan Suárez de Figueroa. Estas últimas habían permanecido agregadas a las de Chámeza y Cusiana hasta 1635 y con la decisión de mantenerlas separadas y entregarlas a otra familia limitaba el poder de los santiagueños sobre los indios de tierra fría, que tradicionalmente habían pertenecido también a la familia Daza; por ende, ponía fin al monopolio sobre el comercio del algodón entre las provincias de Santiago y las de Sogamoso, donde tradicionalmente se vendían los lienzos. Entre los testigos que declararon a favor de la decisión del presidente el vecino 


\section{FRONTERAS}

de la fistoria

Vol.12 / 2007

José López ponía de manifiesto que las comunicaciones entre las tierras frías y calientes eran contraproducentes para la salud de los indios ${ }^{31}$.

También hubo problemas entre jesuitas y santiagueños, esta vez con relación a las entradas o correrías. Esteban Sánchez Chamorro, que había bajado a Guayana con los jesuitas, había recibido al parecer la autorización del padre superior, el francés Antonio Monteverde, que se encontraba en la misión de Aritagua, de repartir ciertos indios entre los soldados (Astrain 6: 652). Según escribe el propio Sánchez, el padre superior le había autorizado sacar ciertos indios bogas para el transporte de la tropa destinada a la Guayana. Este fue el título que le permitió, cuatro años más tarde, cuando los misioneros volvieron al Casanare con 200 indios reducidos, reclamar el derecho de posesión sobre una parte de ellos y salir al paso de la expedición para capturarlos. En febrero de 1669 el jesuita Juan Fernández Pedroche, quien reemplazaba a Monteverde como superior, condenaba a Sánchez Chamorro a la excomunicación si no devolvía los indios que había sacado de las misiones ${ }^{32}$.Los jesuitas reclamaban también que devolviera "los indios del Palmar que se aplicó" y una india llamada María, casada en el Puerto de Casanare, que al parecer vivía con él amancebada. Por su parte Sánchez Chamorro, se defendía ante la Audiencia acusando a los jesuitas:

[...] los amparan, defienden y relevan de trabajo, y los dejan vivir como quieren [y] entre los dichos indios desta nación achaguas, como se comunican unos con otros, se recogen a esta voz los de Santiago y desta jurisdicción [de Cravo], como es manifiesto y público que se han recogido, pues la más cantidad de los indios

\footnotetext{
31 " [...] y que los unos y otros indios son de diversas naciones y sin dependencia unos de otros y de diferentes y contrarios temples por ser los de Santiago de la Atalaya de tierra caliente y los de Pesca y Bombasa de tierra fría, y saliendo a ella los otros cuando no sea más que a traer los tributos al encomendero pueden enfermar y morirse como de diferentes temples y tener de ordinario ellos poco abrigo y ropa y así siente este testigo que deben correr separadas estas encomiendas". AGI, SF 173-26, f. 76.

${ }^{32}$ Una parcialidad había sido sacada de su pueblo de Tate (cerca de Pauto, que era entonces la procuraduría de la misión jesuita). Sánchez Chamorro los había llevado a Tocaría, cerca de San Joseph de Cravo donde vivía y tenia su hacienda de ganado mayor y alegaba su derecho de encomienda diciendo que habían sido agregados por el gobernador a la jurisdicción de San Joseph de Pore donde eran feligreses. Véase AGN (CO 36, f. 19). En efecto, dichos indios le habían sido repartidos en 1655 en la famosa entrada de Francisco Suárez de Vargas en que, como vimos, participó. Pero es probable que los indios huyeran a Pauto desde 1659 cuando los primeros misioneros vinieron a instalar allí su base de operaciones, pues el padre Rivero comentaba a propósito de este pleito que Sánchez no tenía derecho a ellos porque la ley ordenaba que los indios huidos que se redujeren por los misioneros quedasen definitivamente en la real corona. Véase Rivero 241.
} 
que hay hoy en el puerto es de los que se han venido al reclamo de lo sobredicho, dejando sus puestos y doctrinas, y los dichos padres no los consienten sacar del dicho puerto, todo en gran perjuicio de vuestras ciudades y vecinos de ellas. Y como dichos padres, con relaciones siniestras, tienen ganadas vuestras reales provisiones para que ninguna de vuestras justicias no entren en dicho puerto, como de antes lo hacían a cosas de vuestro real servicio, creen los dichos indios lo referido, y dichos padres se soberanizan y engrandecen (cit. en Pacheco 2: 371).

Con todo, las asperezas entre santiagueños y jesuitas parecen haberse ido limando con el tiempo, pues de todas formas los padres, que no eran por entonces más que nueve, necesitaron de la ayuda de los colonos y soldados para sus reducciones. Eso parece desprenderse de la actitud posterior del gobernador Pedro Ordóñez y Vargas, quien al reedificar nuevamente la ciudad de San José de Cravo, que años atrás había fundado su hermano, la bautizaba con el nombre de San José de Beaumont en honor del presidente projesuita muerto hacia 1665 (AGI, SF 173-27, f. 15). Al año siguiente, los informes del gobernador al nuevo presidente eran bastante halagüeño de las actividades evangélicas de la Compañía de Jesús. Además, el gobernador nombraba a su nieto, Pedro Suárez de Vargas Murillo de Guevara, que tenía por entonces 18 años, mariscal de campo para que, como tal, acudiera:

[...] a los reverendos padres misioneros ayudándolos y dándoles todo el favor y ayuda [...] sin que se entienda estando como esta pendiente dicha misión camino seguro de reducción de dichos infieles a nuestra santa fe católica este ni otro título a conquista por medio militar sino para lo contingente que se puede ofrecer y seguridad de dichos misioneros reverendos padres y su ayuda en dicha misión (AGI, $S F$ 173-27, f. 16)

Los padres no desaprovecharon esta oportunidad e hicieron de Pedro Suárez de Vargas un adepto y admirador de la Compañía de Jesús, hasta el punto de que hacia 1690 Pedro recibió Carta de Hermandad por comisión del padre general de los jesuitas. Suárez tenía el cargo de teniente general de Santiago de las Atalayas, que siguió ejerciendo con el mismo título de maestre de campo que su abuelo le había dado casi 30 años antes. Ciertos clérigos de Santiago denunciaban en 1696 todos los excesos y abusos de este personaje, que se había convertido con el tiempo en uno de los hombres más poderosos de Santiago. Además de las hilanzas de algodón, era dueño de un hato de más de 14.000 cabezas de ganado y su encomienda de Caibacoa, que en cifras oficiales contaba 30 indios, según un clérigo pasaba de 200 (AGI, SF 250; Ruiz 365). Entre otras cosas era acusado de haber asentado su residencia, contrariando las 


\section{FRONTERAS}

de la historia

prohibiciones reales, en el pueblo de Caibacoa donde tenía a los indios tejiendo y asistiendo sus ganados, "sin darles el pasto espiritual". También se señalaba que ocupaba a los de los pueblos de Vijua, Cusiana y Aguamena en el trabajo de las minas de sal, la saca de ganado y el arreo de cargas, sin la conveniente paga y que algunos eran de rescate (esclavos) y para su servicio. A propósito de los guahibos, que, como hemos dicho, parecieron colaborar con los santiagueños en las capturas de indios, el documento denunciaba las relaciones privilegiadas que el encomendero mantenía con estos indios desde hacia 30 años pues los tenía:

[...] con [...] privación de oír misa y acudir a doctrina y los indios retirados viviendo en su gentilidad por no experimentar semejante opresión de que se sigue el ver que a los que se mueren les da sepultura en la sabana (AGI, $S F$ 250; Ruiz 365).

Pedro Suárez de Vargas pasó luego al pueblo de Tame, donde fue nombrado a instancia de los jesuitas justicia mayor con el encargo de "poner freno a la insolencia de los españoles" y reducir los tunebos en el nuevo pueblo de Tacoragua que reemplazaba al antiguo de Patute (ARSI, NRQ 13 II, f. 443). No pudimos encontrar información posterior sobre la relación entre este santiagueño y los jesuitas, pero es muy probable que a su muerte, como era tradición entre los amigos de la Compañía, sus bienes, o al menos una parte de ellos, hayan pasado por voluntad testamentaria a engrosar las haciendas de la Compañía de Jesús en los llanos.

Podemos preguntarnos si la llegada de los jesuitas cambió algo en las costumbres de los santiagueños, o si por el contrario fueron los religiosos quienes debieron adaptarse a las prácticas de los colonos. La respuesta es compleja, pues por un lado podemos rastrear una influencia certera de los misioneros en los llanos orientales, donde impusieron en cierta medida los modelos de identidad cristiana no solamente a los indios de misión, sino a los colonos. Los padres consiguieron con el tiempo implantar sus prácticas pastorales y de este modo influir en el comportamiento moral y dirigir las acciones de los colonos, pero esta influencia sólo se hizo perceptible ya bien entrado el siglo XVIII cuando la perseverancia de una política institucional, como la establecida por las órdenes religiosas, recogía sus frutos. Este trabajo a largo plazo empezó desde la segunda mitad del siglo XVII entre los blancos y mestizos instalados en sus haciendas cerca de las pueblos de misión de Pauto, Casanare, Tame, Patute y Macaguane y más tarde, durante el siglo XVIII y hasta la expulsión de 1767, en las ciudades de Cravo, Pore, Chire y Santiago. Los jesuitas sirvieron el curato de Santa Rosa de Chire en varias ocasiones con autorización del gobierno, aunque muchas veces la influencia vino de la 
asistencia de los vecinos a las capillas de las haciendas jesuitas de Caribabare y Tocaría, cercanas respectivamente a las ciudades de Chire, Pore y San José de Cravo. En Santiago de las Atalayas esta influencia se efectuó por la prolongación de su acción en la ciudad de Tunja y de Santafé, donde los jesuitas educaron y confesaron a buena parte de la élite criolla, aunque también mediante continuos actos de jubileo en los que se llevaba la prédica jesuita a la iglesia de los santiagueños. En estas ceremonias tuvieron un importante rol las prácticas confesionales y devocionales. Hacia 1699, por ejemplo, en una de sus visitas, los jesuitas lograron imponer a los santiagueños el culto a san Francisco Javier, levantando un altar en la iglesia de la ciudad. El modelo jesuita de las cofradías indígenas de ganado y de la administración temporal fue también imitado por los recoletos en sus haciendas y misiones.

\section{Decadencia de Santiago en el siglo XVIII (1689-1761)}

Hacia 1685, José de Enciso y Cárdenas, sobrino de Adrián de Vargas, obtenía el gobierno de la provincia de Santiago ${ }^{33}$. En sus capitulaciones se observan ciertos cambios que manifiestan el intento por recuperar el poder que los santiagueños — más concretamente la familia Suárez de Vargas- fueron delegando a lo largo de los años a los jesuitas. En primer lugar, el aumento de la jurisdicción de la ciudad, pues además de las de San José de Cravo y Tuna Puna, que eran puestos fundados por los santiagueños, las capitulaciones añadían las de San Martín y San Juan de los Llanos, que hasta entonces habían sido gobiernos independientes. Las capitulaciones también expresaban el deseo de controlar el acceso y la comunicación del llano con el Orinoco y la Guayana mediante la creación de un real en el sitio de Carichana, cerca de las bocas del Meta. Otro punto importante era la voluntad de intervenir en la actividad misionera mediante el control más estricto de las entradas, la fundación de pueblos y el nombramiento de doctrineros, que fueron campos en los cuales la Compañía de Jesús siempre intentó mantenerse independiente.

Desde 1689, el gobernador inició una serie de denuncias contra los jesuitas que evidencian del ahogamiento en que se encontraba la ciudad a finales del siglo XVII a causa del auge de las misiones. El gobernador los culpaba de ocupar las mejores tierras y de sacar los indios de los pueblos sin pedir concertados al

\footnotetext{
${ }^{33}$ Para posesionarse de su nuevo cargo, Enciso hacia dejación del gobierno de la provincia de San Faustino (cerca de Pamplona) que ejercía desde 1676 y donde había contribuido a la pacificación de los motilones y a la defensa de Gibraltar y Maracaibo contra las amenazas de los piratas franceses (AGN CO 22, f. 166v).
} 


\section{FRONTERAS}

de la fistoria

Vol.12 / 2007

corregidor, de mantener comercio y conducir mercaderías desde la Guayana francesa y de haber permanecido inermes por más de 80 años, más preocupados en la administración de sus pueblos y en la mejora de sus haciendas que en las misiones de nuevos indios ${ }^{34}$. Sobre este último punto se fundaron las acusaciones más contundentes, pues en teoría los misioneros debían dejar los pueblos al clero secular una vez que los indios hubieran completado el proceso de cristianización y pasado el término legal de los 20 años durante los cuales se les exoneraba de tributo. Tampoco era autorizado a los misioneros ejercer su actividad entre los vecinos de las ciudades de españoles, cosa que fue bastante frecuente en los llanos ${ }^{35}$.

Poco a poco la ciudad fue entrando en decadencia, hasta el punto de que a finales del siglo XVIII perdía su estatus de centro de colonización llanero cediéndole el lugar a la ciudad de San José de Pore. En 1778 Pore era la más grande y emprendedora; con sus 1.017 habitantes, casi todos mestizos, tenía bajo su jurisdicción a Manare, Macuco, Ten, Támara, Pital y Morcote, cuatro de los cuales eran centros textiles indígenas manejados antiguamente por misioneros, aunque su prosperidad se debía, ante todo, a la actividad ganadera y a su localización estratégica en el camino entre Casanare, Labranzagrande y Sogamoso (Rausch 105). La región sobrepasaba los 10.000 habitantes, entre los cuales 6.285 , o sea casi el $70 \%$, eran población indígena, lo que representaba

\footnotetext{
34 “9 ${ }^{\circ}$. Si saben que en las orillas del río de Tocaría tienen un hato de ganado muy cuantioso y qué cantidad puede tener, y así mismo otra cantidad de yeguas y burros hechores en que ocupan más de cuarenta leguas, que hay en la jurisdicción de Cravo, pues está reconocido, que en todos los llanos sustentan los vecinos los ganados con sal de vigua y el año que está en liza tiene grande pérdida por la falta de sal, y que en dicho sitio de Tocaría no lo han menester porque hay salitrales y que siendo así, que tienen ocupada toda la tierra referida en perjuicio de los moradores de aquella parte y que sin embargo de esto han formado en las puntas de dicho río y del de Cravo otra hacienda con ganados y yeguas y que estas las mantienen y cuidan con indios que han sacado del Orinoco los quales los tienen en su servicio perpetuamente sin oír misa porque no hay iglesia ninguna donde la oigan y que menos se les enseña la doctrina cristiana y los que mueren los entierran en la sabana" (AHN, CJ 123-9, ff. 2 y 5). Véase también Pacheco (2: 429).

${ }^{35}$ Los vecinos blancos y mestizos que vivían en sus haciendas, acudían como feligreses de los jesuitas en los pueblos de indios e inclusive, muchas veces los padres se desplazaban para administrar los sacramentos, cosa que rara vez hacían los curas. En este sentido, las quejas del gobernador encontraron oídos en el arzobispo de Santafé quien trató de aplicar todo su poder en desacreditar las misiones, hasta tal punto que en Roma, el General Tirso Gonzáles escribía al Provincial pidiéndole examinar la posibilidad de renunciar las misiones de Casanare. Véase la carta del general Tirso Gonzáles al provincial Martínez Rubio (APT 132, f. 130). Pese a ello, ni las misiones fueron renunciadas, ni Enciso pudo deshacerse del poder de los padres, quienes a fuerza de perseverancia lograron obtener su demisión en la primera década del siglo XVIII.
} 
una mano de obra suficiente, si la comparamos con el 43\% de la población indígena presente en la región de Santiago en la misma época ${ }^{36}$.

Pero el auge misional no fue el único factor que contribuyó a la decadencia de Santiago. Las enfermedades y las continuas cacerías de indios ayudaron también a dispersar y disminuir la población indígena. Los achaguas, de los que se decía en el siglo XVI (Morey 238) eran la nación más numerosa de los llanos, experimentaron a mediados del siglo XVIII una enorme baja demográfica. Hacia 1736, el padre Gumilla, por ejemplo, contaba menos de 3.000 en toda la Orinoquía. Tanto las enfermedades como la baja de la tasa de natalidad habían disminuido considerablemente los pueblos reducidos. Los indios morían por cientos y las mujeres indias preferían traer al mundo a hijos mestizos y no a esclavos indios. A esto se sumaba la dispersión de las etnias tradicionales y la concurrencia de los portugueses y holandeses en el mercado de macos. Las correrías y entradas se hicieron cada vez más lejanas y difíciles, razón por la cual los santiagueños abandonaron progresivamente esta actividad para concentrarse en la producción de sus haciendas. Para mediados del XVIII los guahibos habían tomado parte del territorio ancestral de los achaguas en el Meta antes poblado por decenas de miles de indios (Rausch 125). Muchos habían huido hacia el sur, a refugiarse entre los ríos Guaviare, Vichada y Tuparro, donde al cabo del tiempo fueron también apresados por los caribes, o se refugiaron desde 1730 en las misiones jesuitas. Otro factor de la decadencia de la ciudad fue la desaparición del mercado del algodón. A mediados del siglo XVIII casi todos los obrajes habían desparecido. El desarrollo del ganado lanar en las tierras altas y la decadencia del mercado tunjano de lienzos, causada por la nueva producción algodonera del Socorro, fueron factores determinantes en el auge de la ganadería extensiva (Loy 247) y, por ende, del desarrollo de las regiones de Cravo, Pore y Chire, que eran geográficamente más propicias a la ganadería que la región de Santiago.

Para 1761 Santiago se encontraba fundada a orillas del río Aguamena (Gómez 44) adonde había sido trasladada y reedificada por la quinta vez por el gobernador Enciso desde 1689. La ciudad continuaba siendo la capital de la provincia y su gobernador confirmaba los alcaldes de las ciudades de Santa Rosa de Chire, San José de Pore, San Martín y San Juan, estas dos últimas prácticamente despobladas. Los curatos de su jurisdicción eran los pueblos de

\footnotetext{
${ }^{36}$ La información procede del Archivo Histórico Nacional, del padrón del gobernador José Caycedo y Florez Ladrón de Guevara, hecho en Morcote el 14 de octubre 14 de 1779. Véase Loy (244).
} 


\section{FRONTERAS}

de la historia

Surimena, Casimena, Santa Bárbara, Upamena, Chámeza, Labranzagrande, Pisva y Paya. En 1778 unos 2.175 vecinos estaban entonces repartidos entre la ciudad y las haciendas de los alrededores del río Aguamena y Cusiana y de los pueblos de Iximena y Chámeza que concentraban un alto porcentaje de población blanca y mestiza (Loy 244). Los criollos eran, sin embargo, más numerosos que los mestizos y conformaban el $32 \%$ contra el $23 \%$ de mestizos. El estamento más tradicional de la sociedad llanera se encontraba todavía concentrado en la región de Santiago a diferencia de lo que ocurría en Pore donde los criollos no representaban más que el $1,8 \%$ contra $27 \%$ de mestizos. Para esta época los vecinos se encontraban ya divididos en dos poblaciones separadas: Santiago y Chitamena (Rausch 269). Los vecinos más pudientes se habían fundado en Chitamena bautizando la nueva población con el nombre de Barroblanco y argumentaban su traslado por la insalubridad del clima del antiguo puesto ${ }^{37}$. Sin embargo el virrey Flores se mostraba indeciso en oficializar la decisión, pues más de 300 vecinos se habían quedado en el antiguo puesto, que tomó desde entonces el nombre de Santiago Viejo. Esta situación dio origen a un litigio entre los vecinos de ambas poblaciones que se prolongó hasta el siglo XIX, sin lograrse su unificación. Las dos poblaciones continuaron en franco deterioro, hasta llegar a extinguirse entre la segunda y la tercera décadas del siglo XIX y desaparecer para siempre de los mapas de Casanare.

$* * *$

En el territorio de Santiago de las Atalayas, la encomienda no fue el patrón organizador de pueblos y ciudades, excepto en sus inicios, y está ligada a la historia de los llanos, en especial por las élites fundadoras que habían asentado su poder en el corregimiento de Sogamoso. La colonización se emprendió desde allí sobre todo en función de los obrajes de algodón instalados por los santiagueños. La reconstrucción de los linajes de las familias de Santiago de las Atalayas dentro del contexto institucional de las encomiendas es un primer acercamiento al estudio de los nexos entre territorialidad y poder en los antiguos territorios de Santiago y Casanare. Sin embargo, y en la medida en que el modelo de colonización se ha desplazado hacia el fenómeno de la hacienda y el concertaje, esto implica un cambio de dirección en la investigación para seguir los personajes de estos linajes dentro de la estructura eclesiástica (legos, clero regular, clero secular), de la estructura de la misión tal como es concebida por la organización jesuita (hacienda, cofradía, coadjutoría) y de las competencias

\footnotetext{
${ }^{37}$ Por iniciativa del gobernador Domínguez de Tejada se adelantaron en agosto de 1778 los primeros trabajos de reedificación (AGN, $P B$ 2, f. 671).
} 
jurisdiccionales de la organización del poder civil (gobernación, corregimiento, encomiendas reales). Es sólo a través de un estudio cruzado de este tipo como se puede llegar a entender la evolución, adaptación o mutación de los linajes de los encomenderos durante el siglo XVII y hasta la segunda mitad del siglo XVIII, cuando es manifiesta una ruptura.

La crisis de la encomienda de las décadas de 1630 y 1640 afectó igualmente a la región de Santiago. A nuestro modo de ver, incrementó las nuevas fundaciones y la cacería de indios e inició un proceso de colonización eminentemente centrífugo y rural cuyo modelo era la estancia ganadera, por oposición al los obrajes que concentraban la población indígena y española en el piedemonte. La llegada de los religiosos jesuitas a mediados del siglo XVII impuso un primer freno a los desafueros cometidos por los santiagueños. A largo plazo, sin embargo, la institución de la misión se inscribió en la continuidad de los cambios ocurridos en la década de 1630, pues institucionalizó la hacienda como modelo de colonización y de organización económica y social. Al respecto este ensayo plantea varias preguntas que nuevas investigaciones deberían dilucidar y a las que algunos de los apartes de este ensayo responden imperfectamente.

Si los obrajes de algodón y las haciendas de ganado fueron procesos opuestos y correspondieron a la mutación de la encomienda hacia el sistema de la hacienda y el concierto, ¿en qué momento y por cuál proceso se efectuó esta mutación en la región de Santiago? En su análisis de las haciendas jesuitas de Casanare, la historiografía ha dejado de lado el periodo comprendido entre 1659 y 1767, en el cual se consolidaron no solamente las misiones y haciendas jesuitas, sino también las ciudades y haciendas particulares de los colonos de Santiago de las Atalayas.

¿Cuál fue el papel de la misión en este proceso y por cuáles mecanismos se precisó concretamente? Aunque el papel de las haciendas jesuitas de Tocaría y Apiay fue importante, es claro que los hatos ganaderos no fueron una iniciativa solamente jesuita, como lo demuestra el impulso privado que de la parte de los Chamorro y los Suárez de Vargas recibieron en sus inicios las haciendas de la Compañía de Jesús. Sería interesante dirigir hacia esta dirección la investigación para entender mejor el origen de los hatos ganaderos y las relaciones entre las haciendas jesuitas y los colonos propietarios de Santiago de las Atalayas.

En esta misma dirección debería también efectuarse una apertura que nos permita entender mejor las formas de dominación de la misión y la hacienda. 


\section{FRONTERAS}

de la historia

Tratándose del manejo de los indios, la imagen de las encomiendas reales (misiones) es bastante positiva en relación con la de los vecinos encomenderos y terratenientes, pero es cierto también que esta diferencia nace de una comparación cualitativa entre dos tipos opuestos de documentos. Por un lado tenemos la imagen positiva, panegirista que las propias órdenes nos dan de sus misiones, y por el otro, los datos sistemáticamente negativos de los abusos de los colonos que aparecen en los pleitos y quejas de indios. En este sentido, un trabajo de revisión de estas imágenes merece ser llevado a cabo para determinar en qué medida y de qué forma la misión-institución se corresponde con el fenómeno de la estancia privada y del concertaje.

\section{Glosario}

Cimarroneras: lugares donde se encuentra ganado salvaje. Se aplicó también a las regiones no conquistadas donde vivían indios no sometidos o refugiados de las encomiendas.

Cofradías: congregaciones laicas de indios instituidas por la misión; eran propietarias de hatos de ganado para el sustento de las iglesias.

Concertaje: contrato de trabajo obligatorio para los indios.

Entrada: expedición o correría.

Maco: esclavo.

Mayorazgo: patrimonio familiar que, según la institución antigua, retransmite siempre al hijo mayor.

Parcialidades: tribus o etnias indígenas; también puede referirse al nombre de sus pueblos.

Pieza: indios capturados. Palabra usada en los siglos XVI y XVII por los colonos españoles; proviene de voz más general con la que se designaban las fieras o animales de caza. 


\section{Bibliografía}

\section{Fuentes primarias}

Archivo General de Indias, Sevilla, España (AGI)

Audiencia de Santafé (S) 26, 51, 79, 171, 173, 177, 249, 250.

Archivo General de la Nación, Bogotá, Colombia (AGN).

Caciques e Indios (CI) 25.

Curas y Obispos $(\mathrm{CO}) 22,36$.

Encomiendas (E) 2, 12, 16.

Poblaciones de Boyacá (PB), 2.

Tierras de Boyacá (TB) 21.

Visitas de Boyacá (VB) 1.

Archivo Histórico Nacional, Madrid, España (AHN).

Clero. Jesuitas $(C J) 123$.

Archivo Provincial de Toledo, Alcalá de Henares, España (APT)

Archivo Romano Societatis Jesu, Roma, Italia (ARSI).

Novo Regno et Quito (NRQ) 13 II.

Fondo Pastells de la Universidad de Comillas, Madrid, España (FPC)

\section{Fuentes secundarias}

Acosta Saignes, Miguel. Estudios de etnología antigua de Venezuela. Caracas: Universidad Central de Venezuela, 1961.

"Acta de fundación de la ciudad de Santiago de las Atalayas". Revista del Archivo Nacional 6 (1944): 46. 


\section{FRONTERAS}

de la historia

Vol.12 / 2007

Astrain, Antonio, S.J. Historia de la Compañía de Jesús en la asistencia de España. 7 t. Madrid: Sucesores de Rivadeneyra, 1902-25.

Colmenares, Germán. La provincia de Tunja en el Nuevo Reino de Granada. Bogotá: Tercer Mundo, 1997.

Cortés Alonso, Vicenta. “Tunja y sus vecinos”. Revista de Indias 25 (1965): 155-207.

Fabo, fray Pedro. Idiomas y etnografia de la región oriental de Colombia. Barcelona: José Benet, 1911.

Ganuza, Marcelino. Monografia de las misiones vivas de agustinos recoletos (candelarios) en Colombia. Siglo XVII-XX. Bogotá: Imprenta de San Bernardo, 1920.

Gómez López, Augusto, Guido Barona Becerra y Camilo Domínguez Ossa, eds. Viaje de la Comisión Corográfica por el Territorio de Casanare 1856: obra dirigida por el general Agustín Codazzi. Bogotá: I/M, 2000.

Langebaek, Carl H. "Sistemas de comunicación prehispánica entre los Andes orientales y el piedemonte llanero". Caminos Reales de Colombia. Bogotá: Fondo FEN Colombia, 1995.

Loy, Jane M. "Forgotten Comuneros: The 1781 Revolt in the Llanos of Casanare". The Hispanic American Historical Review 61.2 (1981): 23557.

Morey, Nancy. "Foragers and Farmers: differential consequences of Spanish contact". Ethnohistory 20.3 (1973): 229-46.

Mörner, Magnus. La corona española y los foráneos en los pueblos de indios de América. Madrid: Ediciones de Cultura Hispánica, 1999.

Pacheco, Juan Manuel, S. J. Los jesuitas en Colombia. 3 t. Bogotá: San Juan Eudes, 1959-1989.

—. "La consolidación de la iglesia - Siglo XVII". Historia Eclesiástica I. Bogotá, 1975.

Pelleprat, Pierre. Relation des Missions des PP. de la Compagnie de Iesus dans 
les Isles, \& terre ferme de l'Amerique meridionale. París: Sebastien Cramoisy, 1655.

Pérez Ángel, Héctor P. La hacienda Caribabare. Yopal, Colombia: Corpes Orinoquía, 1997.

Rausch, Jane M. Una frontera de la sabana tropical los llanos de Colombia 1531-1831. Bogotá: Banco de la República, 1994.

Recopilación general de las leyes de las Indias. 4 t. Madrid: Vicente Gonzaga, 1680.

Restrepo Echavarría, Emiliano. Una excursión al territorio de San Martín en diciembre de 1869. Bogotá: Banco de la República, 1955.

Rivero, Juan. Historia de las misiones de los llanos de Casanare y los ríos Orinoco y Meta. Bogotá: Presidencia de Colombia, 1956.

Rueda Méndez, David. Las encomiendas de Santiago de las Atalayas. Tunja: Universidad Pedagógica, 1996.

Ruiz Rivera, Julián. Encomienda y mita en Nueva Granada. Sevilla: Escuela de Estudios Hispanoamericanos, 1975.

Simón, fray Pedro. Noticias historiales de las conquistas de Tierra Firme en las Indias Occidentales. 7 t. Bogotá: Banco Popular, 1981.

Solórzano y Pereyra, Juan de. Política indiana. 3 t. Madrid: Fundación José Antonio de Castro, 1996.

Vilar y Pascual, Luis. Diccionario histórico-genealógico y heráldico de las familias de la monarquía. Madrid: Librería de Don M. Guijarro, 1859.

Zamora, fray Alonso, O. P. Historia de la Provincia de San Antonino del Nuevo Reino de Granada. 4 t. Bogotá: Instituto Colombiano de Cultura, 1980.

Fecha de recepción: 6 de febrero de 2007.

Fecha de aprobación: 30 de julio de 2007. 